TI 2018-066/V

Tinbergen Institute Discussion Paper
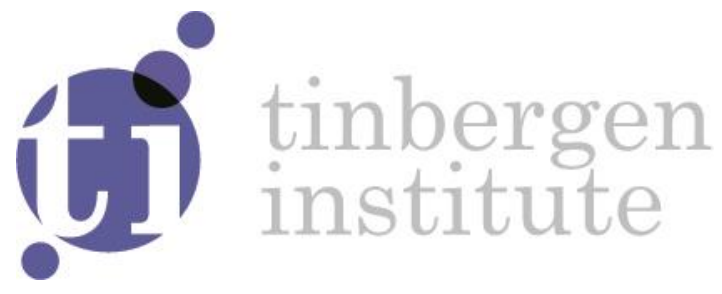

\title{
Every crisis has a silver lining? Unravelling the pro-cyclical pattern of health inequalities by income
}

Max Coveney 1

Pilar (P.) Garcia-Gomez ${ }^{1}$

Eddy (E.K.A.) van Doorslaer ${ }^{2}$

Tom (T.G.M.) van Ourti ${ }^{1}$

${ }^{1}$ Erasmus School of Economics, Erasmus University Rotterdam

${ }^{2}$ Erasmus School of Health Policy and Management, Erasmus University Rotterdam 
Tinbergen Institute is the graduate school and research institute in economics of Erasmus University Rotterdam, the University of Amsterdam and VU University Amsterdam.

Contact: discussionpapers@tinbergen.nl

More TI discussion papers can be downloaded at http://www.tinbergen.nl

Tinbergen Institute has two locations:

Tinbergen Institute Amsterdam

Gustav Mahlerplein 117

1082 MS Amsterdam

The Netherlands

Tel.: +31(0)205984580

Tinbergen Institute Rotterdam

Burg. Oudlaan 50

3062 PA Rotterdam

The Netherlands

Tel.: +31(0)10408 8900 


\title{
Every crisis has a silver lining?
}

\section{Unravelling the pro-cyclical pattern of health inequalities by income}

\author{
Max Coveney ${ }^{\mathrm{a}}$ Pilar García-Gómez ${ }^{\mathrm{a}}$, Eddy Van Doorslaer ${ }^{\mathrm{a}, \mathrm{b}}$, Tom Van Ourti ${ }^{\mathrm{a}}$ \\ a Erasmus School of Economics, Erasmus University Rotterdam, P.O. Box 1738, 3000 DR Rotterdam, the \\ Netherlands; Tinbergen Institute, and NETSPAR \\ ${ }^{b}$ Erasmus School of Health Policy and Management, Erasmus University Rotterdam, P.O. Box 1738, 3000 DR \\ Rotterdam, the Netherlands
}

\section{May 2018}

\begin{abstract}
It is well known that income and health are positively associated. Much less is known about the strength of this association in times of growth and recession. We develop a novel decomposition method that focuses on isolating the roles played by government transfers versus market transfers on changes in income-related health inequality (IRHI) in Europe. Using the European Union Survey of Income and Living Conditions (EU-SILC) panel data for 7 EU countries from 2004 to 2013, we decompose the changes in IRHI while focusing on possible effects of the 2008 financial crisis. We find that such inequalities rise in good economic times and fall in bad economic times. This pattern can largely be explained by the relative stickiness of old age pension benefits compared to the market incomes of younger groups. Austerity measures are associated with a weakening of the $\mathrm{IRHI}$ reducing effect of government transfers.
\end{abstract}

\footnotetext{
${ }^{1}$ E-mail addresses: coveney@ese.eur.nl (Max Coveney) (corresponding author); garciagomez@ese.eur.nl (Pilar GarcíaGómez); vandoorslaer@ese.eur.nl (Eddy van Doorslaer); vanourti@ese.eur.nl (Tom Van Ourti).

We acknowledge support from Netspar, under the Comparative Research grant. This study is based on data from Eurostat, EU Statistics on Income and Living Conditions 2004-2013. The responsibility for all conclusions drawn from the data lies entirely with the authors. We thank seminar participants at the Netspar Pension Day 2017, HESG Winter 2018 Conference and the Netspar International Pension Workshop 2018 for useful comments and suggestions. The usual caveats apply, and all remaining errors are our responsibility.
} 


\section{Introduction}

It is well known that those with higher incomes enjoy longer and healthier lives than those with lower incomes. These inequalities, which are widespread and persistent, have presented a challenge to policy makers and researchers. Both the Centre for Disease Control in the US and the European Commission have highlighted the need to reduce disparities in health, and have devoted resources to doing so (CDC, 2013; European Commission, 2009).

However, despite these concerns, important gaps remain in our understanding of these inequalities. Firstly, relatively little is known about how Income Related Health Inequality (IRHI) in Europe has changed since the Great Recession. While changes in the income distribution have been well documented (Jenkins et al, 2012), comprehensive cross-country evidence on changes in the distribution of health by income before, during and after the crisis is lacking. ${ }^{2}$ Without precise estimates of IRHI over this period, we currently miss important information that is necessary to address these inequalities.

Secondly, evidence is also lacking on the relative importance of (changes in) different income sources for (changes in) IRHI. We distinguish between the two most important sources of income: market incomes (like wages), and government transfers (like old-age and unemployment benefits) and separate their influence on IRHI. Why is it plausible that changes in these different income sources have differing IRHI consequences? First, because their distribution across age and health groups differs, and secondly, because they tend to vary in opposite directions in times of recession and growth. The distinction is also important because of its implications for policy; governments are able to manipulate transfers such as unemployment benefits more directly than, for example, wages. The crisis induced heterogeneous labor market effects across nearly all European countries and governments responded differently with a range of austerity measures, primarily relating to unemployment and pension benefits. Further, if there is a distinct role of transfer income for IRHI changes, then it is important to shed light on some of the - perhaps unintended - IRHI consequences that policies governing these transfers may have had.

Our contributions are fourfold. First, we document trends in IRHI in 7 European countries ${ }^{3}$ between 2004 and 2013 - both before and after the financial crisis. Second, we develop a novel decomposition method that identifies the separate roles of government transfers and market earnings on the evolution of IRHI. Third, by means of the decomposition, we unravel the most important drivers of the

\footnotetext{
${ }^{2}$ Ásgeirsdóttir \& Ragnarsdóttir (2013) study differences in IRHI for 26 European countries in 2007. However, this cross-sectional approach is uninformative about the evolution of IRHI between 2004 and 2013.

${ }^{3}$ Austria, Belgium, France, Greece, Italy, Portugal and Spain.
} 
distinctive patterns that we observe for IRHI pre- and post-crisis. Lastly, we provide descriptive evidence on the role that specific pension policies, and the austerity measures enacted in Greece, have had on IRHI.

We add to the literature using rank-dependent, concentration index-type measures to compare health inequalities by income across countries that started with Van Doorslaer et al (1997). Subsequent contributions have employed a series of decomposition methods and measurement corrections that provided additional insight into the drivers of cross-country differences (Van Doorslaer and Koolman, 2004; Van Ourti et al, 2009). These and other European comparative studies report substantial prorich inequalities in health in Europe, and they highlight the role of changes in the income ranks, in addition to health, for inequality trends.

Coveney et al (2016) used a decomposition of concentration indices to study IRHI changes in Spain between 2004 and 2012. Though IRHI was initially growing between 2004 and 2008 as the Spanish economy grew, large reductions in inequality occurred after $2008 .{ }^{4} \mathrm{~A}$ decomposition analysis of these trends reveals that IRHI was primarily driven by the income position of the relatively unhealthy elderly groups. In "good" economic times, the income position of the young tended to rise faster than that of the elderly, increasing the income gap between the healthy and the unhealthy and subsequently leading to increases in IRHI. During bad economic conditions, incomes of the young fell while incomes among the elderly tended to be far more stable, leading to decreases in IRHI. While these findings hint at the distinct roles played by government transfers versus income from labor, the decomposition methods used did not explicitly allow for this distinction. Further, studying a range of European countries, with differing levels of exposure to the crisis as well as a range of different pension and other policies, provides further insights into the determinants of trends in IRHI.

We do not aim to add to the literature that started with Ruhm (2000), linking health and economic conditions, aiming to identify a causal effect of the crisis or income on health. Rather, our decomposition illustrates how changes in transfer and market incomes are related to changes in the association between income and health, and thus IRHI. By following cohorts of individuals over time in relation to the underlying income and health distributions, our approach also differs from the crosscountry comparisons of Mackenbach and co-authors (1997; 2008, among others), which document levels and trends in socio-economic inequalities in health (mostly education- and occupation-related) for a large number of European countries.

\footnotetext{
${ }^{4}$ This is in line with Regidor et al (2016) who - using a different methodology - conclude that all-cause mortality declined more rapidly during the economic crisis among groups with low socioeconomic status.
} 
Our findings are as follows. First, we find that IRHI trends are interwoven with macroeconomic conditions. Documenting annual IRHI changes across 7 European countries between 2004 and 2013, we find differential trends that imply IRHI is pro-cyclical: perhaps surprisingly, inequalities tend to increase in good economic times and fall in bad times. Between 2004 and 2008, a time of relatively steady economic growth in Europe, IRHI was on average relatively flat, though it significantly increased in countries with substantial economic growth, such as Greece and Spain. Between 2008 and 2012, IRHI fell in countries that were most affected by the crisis, namely Greece, Spain and Portugal. IRHI in countries that did not experience severe economic consequences as a result of the crisis, such as France and Austria, remained stable or increased slightly.

Second, by decomposing these changes, we find that in general the two main sources of household income - market income and government transfers - have opposite effects on IRHI. Market income growth is associated with increasing health inequalities, while rising government transfers tend to reduce them. This stems from the fact that market incomes are on average afforded to the healthy, while government transfers, especially pensions, are on average afforded to both the unhealthiest and poorest individuals in the population.

Third, related to the first and second finding, we show that the pro-cyclical pattern of IRHI can largely be explained by the differing importance of government transfers and market incomes in good economic versus bad economic conditions. The economic crisis led to differential income changes by age-group, and thus by health status. Thus, if income from work grows more (less) than pensions during good (bad) economic times, IRHI grows (falls), in particular when the relative income position of the (unhealthy) very elderly is affected.

Lastly, we present descriptive evidence that both household structure and policies governing pensions across countries have a measurable impact on IRHI. Households where intergeneration sharing of pensions is high, as well as pension reforms Greece enacted as part of the austerity measures in 2010 and 2011, both appear to have dampened the IRHI reducing effect of government transfers. Further, given the importance of the income position of the very elderly in determining IRHI trends, we conclude that policies governing the generosity of pensions for this group, such as indexation policies, can play a role in governing these trends. 


\section{Decomposition of changes in income-related health inequality}

Our decomposition method is based on an extension of the method used in Baeten et al (2013). In this section we describe the approach for a balanced cohort of $n$ individuals that we observe at the start (period 1) and end (period 2) of a time interval.

\section{Health inequality measurement}

To measure health inequalities we use the corrected concentration index (CCI) (Erreygers, 2009) which satisfies the mirror condition and is insensitive to equal health additions (absolute inequality) (Erreygers \& Van Ourti, 2011). When health is bounded between 0 and 1, the index can be written as:

$$
\operatorname{CCI}\left(h_{t} \mid y_{t}\right)=\frac{8}{n^{2}} \sum_{i=1}^{n} z_{i t} h_{i t}
$$

where $h_{t}$ and $y_{t}$ are the health and income distribution in period $t=1$ or $2, h_{i t}$ describes the health level of individual $i$ and $z_{i t}$ is a weight that depends linearly on the income rank of individual $i$ with individuals ranked from poor $(i=1)$ to rich $(i=n)$, i.e. $z_{i}=(2 i-n-1) / n$. This income weight takes the value 0 for the individual with median income, and increases linearly with income rank.

\section{Health model}

We use a simple descriptive model that links health linearly and additively to its associated factors:

$$
h_{i t}=\alpha+\theta\left(y_{i t}\right)+x_{i t}^{\prime} \beta
$$

where $\alpha$ is an intercept parameter; $\theta\left(y_{i t}\right)$ is a non-linear function of income; $x_{i t}$ represents a vector of $K$ non-income variables (in our analysis, these are a set of age-sex and region dummies), and $\beta$ is its associated parameter vector reflecting partial associations. The exact functional form for $\theta(\quad)$ predetermines the sign and magnitude of some parts of our decomposition. Therefore we use a flexible functional form in the empirical application.

\section{Decomposition of IRHI change}

Our interest lies in decomposing changes in IRHI. Taking the change in the $\mathrm{CCl}$ between two periods and combining equation (2) and (1) leads to

$$
\begin{array}{r}
\operatorname{CCI}\left(h_{2} \mid y_{2}\right)-\operatorname{CCI}\left(h_{1} \mid y_{1}\right)=\frac{8}{n^{2}}\left[\sum_{i=1}^{n} z_{i 2} h_{i 2}-\sum_{i=1}^{n} z_{i 1} h_{i 1}\right] \\
=\frac{8}{n^{2}} \sum_{i=1}^{n}\left\{\left[z_{i 2} \theta\left(y_{i 2}\right)-z_{i 1} \theta\left(y_{i 1}\right)\right]+\beta\left[z_{i 2} x_{i 2}^{\prime}-z_{i 1} x_{i 1}^{\prime}\right]\right\}
\end{array}
$$


Equation (3a-b) shows that we can disentangle the change in IRHI into a part due to changes in the association between the income rank and the non-linear income function $\left(z_{i 2} \theta\left(y_{i 2}\right)-z_{i 1} \theta\left(y_{i 1}\right)\right)$ and a part due to changes in the association between the income rank and the non-income factors $\left(z_{i 2} x_{i 2}^{\prime}-z_{i 1} x_{i 1}^{\prime}\right) .^{5}$

Because the aim is to separate the role of different income sources for the change in IRHI, we distinguish between total income $\left(y_{i t}\right)$ as the sum of market incomes $\left(y_{i t}^{M}\right)$ and government transfers $\left(y_{i t}^{T}\right)$, i.e. $y_{i t}=y_{i t}^{M}+y_{i t}^{T}$. Income weights can then be defined separately for each source. Weights associated with total income $\left(z_{i t}\right)$ and market income $\left(z_{i t}^{M}\right)$ are defined in the standard way described above. The income weights associated with transfers are defined as the difference between an individual's total income rank and market income rank:

$$
z_{i t}^{T}=z_{i t}-z_{i t}^{M}
$$

An individual's transfer income rank thus not necessarily coincide with the rank of $y_{i t}^{T}$, but measures the number of steps on the income ladder that separate total from market income. In our descriptive setting this coincides - as is common in the income redistribution literature (Plotnick, 1981; Lambert, 2001) - with interpreting market income as the income that would prevail in the absence of government transfers, or in other words with the redistributive effect of government transfers.

Combining our model for health (equation 2), our definition of transfer income weights (equation 4), and after manipulating the terms in equation $3 \mathrm{~b}$, the change in IRHI between periods 1 and 2 can be expressed as the sum of 5 terms:

$$
\begin{aligned}
& \operatorname{CCI}\left(h_{2} \mid y_{2}\right)-\operatorname{CCI}\left(h_{1} \mid y_{1}\right) \\
& =\frac{8}{n^{2}} \sum_{i=1}^{n}\{\underbrace{\left(z_{i 2}^{M}-z_{i 1}^{M}\right) \sum_{j=1}^{k} x_{j i 2} \beta_{j}}_{\text {market-related income mobility }}+\underbrace{\left(z_{i 2}^{T}-z_{i 1}^{T}\right) \sum_{j=1}^{k} x_{j i 2} \beta_{j}}_{\text {transfer-related income mobility }} \\
& +\underbrace{z_{i 2}^{M} \theta\left(y_{i 2}^{M}\right)-z_{i 1}^{M} \theta\left(y_{i 1}^{M}\right)}_{\text {market-related inequality } \Delta}+\underbrace{\left[z_{i 2} \theta\left(y_{i 2}\right)-z_{i 2}^{M} \theta\left(y_{i 2}^{M}\right)\right]-\left[z_{i 1} \theta\left(y_{i 1}\right)-z_{i 1}^{M} \theta\left(y_{i 1}^{M}\right)\right]}_{\text {transfer-related inequality } \Delta} \\
& +\underbrace{z_{i 1} \sum_{j=1}^{k} \beta_{j}\left(x_{j i 2}-x_{j i 1}\right)}_{\text {ageing and migration }}\}
\end{aligned}
$$

\footnotetext{
${ }^{5} \mathrm{An}$ additional assumption is that there is no structural change in the health equation across periods.
} 


\section{Explanation of decomposition terms}

We term the first two expressions in equation 5 market-related income mobility and transfer-related income mobility respectively. Market-related income mobility measures the association between changes in the market income weights/ranks and non-income related health in the second period. The expression between brackets captures the change in an individual's market income weights/ranks between period 1 and 2, and will be positive (negative) if an individual has moved up (down) in the market income ranks. The second part of the term captures the non-income related health of the individual in the second period. The transfer-related income mobility term is identical, except for the use of transfer income weights. Both income mobility terms are more positive (negative) when upwardly (transfer/market) income mobile individuals have better (worse) non-income health in period 2, or vice versa.

Note that if the non-income variables consist of multiple variables that enter the health equation additively, then the mobility terms comprise a summation of different sub-terms. This holds, for example, if one uses a set of age-sex and region dummies as we do. This allows one to separate the aggregate mobility effect into the contribution per age-group and region category. Summing the total transfer and market mobility terms gives the total income mobility.

The third expression in equation 5 is termed market-related inequality change. It measures the consequences for IRHI of the change in the distribution of market incomes. $\theta\left(y_{i 2}^{M}\right)$ denotes the health level in the second period that corresponds to $y_{i 2}^{M}$ conditional on the non-income factors. The first product therefore measures market related inequality in the conditional health levels. This is simply the $\mathrm{CCl}$ for market income related health in the second period. The second product in the expression is identical, but refers to the first period. The difference between these two corrected concentration indices therefore captures how changes in the distribution of market incomes between the two periods were associated to changes in IRHI, both by their association with health through the $\theta()$ function, and via the re-ranking of individuals on the market income scale. For a monotonically increasing $\theta()$ function, market-related inequality change will indicate rising (falling) IRHI when the rich (poor) predominantly experience income improvements (deteriorations).

The fourth expression in equation 5 is the transfer-related inequality change. Term $\left[z_{i 2} \theta\left(y_{i 2}\right)-\right.$ $\left.z_{i 2}^{M} \theta\left(y_{i 2}^{M}\right)\right]$ captures the degree to which transfer incomes change the association between income weight/rank and income-related health in the second period; the second term measures this effect in the first period. Both terms thus reflect whether transfer incomes result in a more or less equal distribution of income-related health, or the extent of the redistributive effect of transfer incomes in the separate periods. Their difference is a measure of how this effect has changed over time, and its 
consequence for the evolution of IRHI. Summing market-related inequality change and transferrelated inequality change gives the change in the $\mathrm{CCl}$ for total income-related health between periods 1 and 2.

Finally, any remaining change in IRHI is captured by the ageing and migration term. It indicates how changes in non-income related health, due to their association with initial income weights/ranks, have led to changes in IRHI. As our non-income variables are age-sex and region dummies, it therefore measures the impact of ageing and within-country migration on IRHI. As these phenomena have consequences for health, the degree to which they are associated with income ranks may affect IRHI. This term mainly acts as a control, allowing us to study changes in IRHI net of ageing and migration effects. 


\section{Empirical analysis}

Data

We use the European Union Survey on Income and Living conditions (EU-SILC), a European-wide survey designed primarily to collect labor and income related data. It is well suited to our analysis for several reasons. First, it provides a detailed breakdown of the sources of disposable household income, which is crucial to measuring the separate effects of government transfers and market income on IRHI trends. Secondly, individuals are asked to rate their self-assessed health (SAH), which is used as our health measure.

Our selection of countries is based on data availability and quality in the EU-SILC. We require that countries have adequate income and health data for the whole 2004-2013 period. Table A1 in the appendix provides information on the available information for the 29 EU-SILC countries and the selection criteria used for inclusion. This leaves us with the following 7 countries: Austria, Belgium, France, Portugal, Italy, Greece and Spain. ${ }^{6}$ Crucially, the latter 4 countries are of particular interest because they were more affected by the 2008 financial crisis.

The EU-SILC is a rotating panel. A new random sample (referred to as a rotation group) is drawn every year, followed for 4 years and then dropped. Therefore, at any point, each country has 4 concurrent panel samples. There are 7 rotation groups in our study period, i.e. 2004-2007, ..., 2010-2013. ${ }^{7}$ We use balanced data from all 7 rotation groups to estimate our model for health (equation 2). ${ }^{8,9}$ Table 1 gives the number of observations per rotation group and country. Due to changes in data collection methods, the income data for France from 2009 onwards are not comparable to earlier waves. We therefore ignore the 2007-2010 period for France ${ }^{10}$.

\footnotetext{
${ }^{6}$ Our selection criteria is that a country is represented in all 7 rotation groups. Furthermore, although many of the Nordic countries - Finland, Iceland and Sweden - are present in rotation groups, their use of register-based data collection methods leads to many missing values of the SAH variable raising concerns of attrition bias. Sample sizes in some of these countries are too low for reliable analysis. For instance, there are only 13 women above the age of 75 in the 2004 sample in Iceland. Table A1 details the selection criteria per country.

${ }^{7}$ The French EU-SILC uses longer rotation groups, but for comparability with other countries we shorten them to 4 years.

${ }^{8}$ We symmetrically drop the top and bottom $1 \%$ of total income to remove potential outliers.

${ }^{9}$ Our restriction to balanced panels excludes the possibility of attrition bias. However, trends of IRHI computed when using all data, not just a balanced panel - are extremely similar to those we find here, suggesting attrition bias is not driving our results.

${ }^{10}$ The data collection method for certain components of income in France, namely "interest, dividends and profit from capital investments in unincorporated business", went from being survey-based to register-based in 2009. The average value of this component increased by almost $€ 3,000$, and led to a dramatic rise in average incomes. It is not possible to distinguish between "real" increase in the component and inflation due to more accurate collection methods.
} 
Table 1 - Observations per wave, rotation group, country in EU-SILC dataset

\begin{tabular}{llllllll}
\hline Rotation group & $\mathbf{1}$ & $\mathbf{2}$ & $\mathbf{3}$ & $\mathbf{4}$ & $\mathbf{5}$ & $\mathbf{6}$ & $\mathbf{7}$ \\
\hline Period & & & & & & & \\
& $2004-2007$ & $2005-2008$ & $2006-2009$ & $2007-2010$ & $2008-2011$ & $2009-2012$ & $2010-2013$ \\
Observations & & & & & & & \\
Austria & & & & & & & \\
Belgium & 2,294 & 1,923 & 1,901 & 1,894 & 1,882 & 2,200 & 2,163 \\
Greece & 1,315 & 2,126 & 1,966 & 1,987 & 1,670 & 1,762 & 1,886 \\
Spain & 2,221 & 2,113 & 2,498 & 2,238 & 2,756 & 2,479 & 2,244 \\
France & 4,136 & 4,918 & 5,046 & 5,474 & 5,522 & 5,177 & 4,571 \\
Italy & 1,433 & 2,323 & 2,360 & 2,359 & 2,399 & 2,295 & 2,316 \\
Portugal & 8,240 & 7,898 & 7,673 & 7,709 & 6,730 & 5,652 & 4,986 \\
\hline
\end{tabular}

Table shows for each rotation group the period spanned and the number of balanced observations (observed for the whole 4 year period) for each country.

Income and health measurement

The EU-SILC provides, per person and household, a detailed breakdown of the components of annual household income. We separate total income into what we term market income and transfer income. An individual's market income is defined as the equivalized ${ }^{11}$ value of disposable household income before all social transfers, and transfer income as the equivalized value of the sum of all household social transfers. The income reference period is the previous calendar year. Table 2 lists the EU-SILC components that make up household market and transfer income.

What is the relative importance of each of these components? Public pensions form the largest share of transfer income, and employee income (income from work) for market incomes. ${ }^{12}$ When using the term "pensions" we are referring to what EU-SILC terms "old age" benefits. These include the collection of all social payments to the elderly that are designed to provide a replacement income when a person has reached a certain age. ${ }^{13}$

\footnotetext{
${ }^{11}$ Our equivalization procedure involves dividing household income by the square root of the number of individuals living in the household in the current period.

${ }^{12}$ Table A2 in the appendix shows the percentages of transfer and market incomes that are made up of pensions and wages respectively, per rotation group and country.

${ }^{13}$ This includes public pension payments, care allowances, disability cash benefits, lump sum payments at the time of retirement and other cash benefits. It does not include any payments from private pension plans, which enter the market income definition. See the EU-SILC guidelines documentation for further details. Our data shows private pensions are not an important part of transfers for these countries. On average across all rotation groups and countries, payment from private plans are less than $1 \%$ of old age benefits. Per country, the average fraction of private payments to pension payments is never higher than $3 \%$.
} 
The other key variable in our analysis is the self-assessed health variable. Individuals are asked the following question: "How is your health in general? Is it: (1) very good, (2) good, (3) fair, (4) bad, (5) very bad?"

Table 2 - Income components of transfer and market incomes

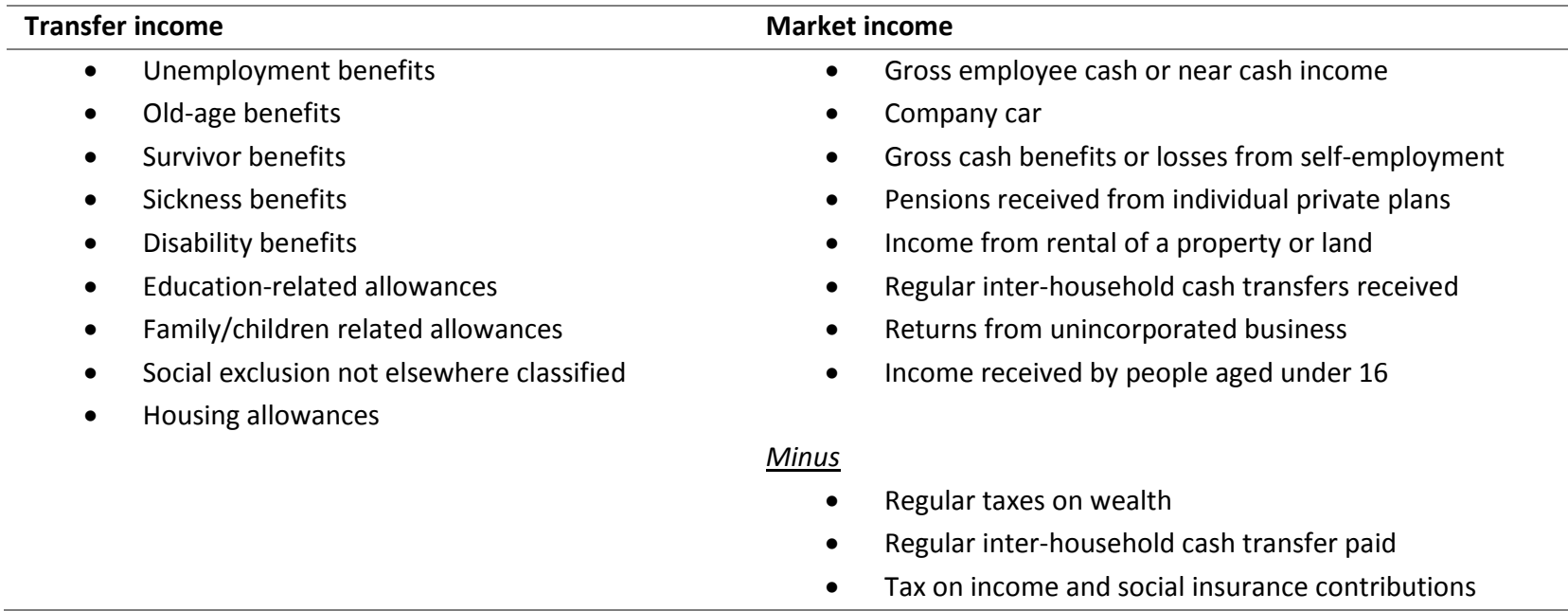

Table shows the makeup for our definitions of Transfer and Market incomes as used in the EU-SILC survey. Importantly, oldage benefits captures all benefits that provide a replacement income once an individual retires or reaches a certain age. This includes public pension payments, care allowances, disability cash benefits, lump sum payments at the time of retirement and other cash benefits. It does not include any payments from private pension plans, which enter the market income definition. Disability and other payments also appear as a separate category, as this captures these payments when they are afforded to individuals who have not retired.

\section{Implementation of decomposition}

The first step in the decomposition procedure is to calculate, per country, rotation group and year, IRHI using the $\mathrm{CCl}$. The $\mathrm{CCI}$ requires a ratio-scaled health measure (Erreygers \& Van Ourti, 2011). In order to transform the ordinal SAH measure in EU-SILC to a ratio-scaled measure, we use an interval regression with the threshold values imposed from external data (Van Doorslaer \& Jones, 2003). ${ }^{14}$ The variables included in these regressions are age/sex dummies ${ }^{15}$, region dummies ${ }^{16}$ and a second degree income polynomial, in line with the widely observed concave shape of the health-income gradient. This predictive set of variables is parsimonious, yet is strongly associated with health. The interval

\footnotetext{
${ }^{14}$ Our imposed thresholds are from the empirical distribution function of the health utility index in the Canadian National Population Health Survey 1994-1995.

${ }^{15}$ The age/sex dummies divide age into the following categories, separately for men and women: 16 to 25 years, 26 to 35 years, 36 to 45 years, 46 to 55 years, 56 to 65 years, 66 to 75 years, and more than 75 years of age.

${ }^{16}$ Regions in EU-SILC are recorded at the NUTS II level. For Portugal and Belgium however this information is missing and we use urbanization dummies (dense, medium and thinly populated areas) instead.
} 
regression is run separately for each country ${ }^{17}$. and serves a dual purpose: (i) they produce a ratioscaled predicted health score between 0 and 1 , and (ii) they provide the non-income and income coefficients $\left(\beta_{j}\right.$ and $\left.\theta().\right)$ used in the decomposition (equation 5$)$. The regression results for each country are shown in the appendix, in table A3.

For each country, we then take 3 rotation groups (2004-2007, 2007-2010, 2010-2013), and calculate and decompose the change in the $\mathrm{CCl}$ from the first year (the base year). We only present the decomposition with respect to the last year of the rotation group because intermediate decompositions are similar in sign and relative magnitude within rotation groups. ${ }^{18}$ In order to allow for statistical inference on IRHI levels, IRHI changes and the decomposition terms, we bootstrap the entire procedure.

\footnotetext{
${ }^{17}$ While we only explicitly decompose the 2004-2007, 2007-2010 and 2010-2013 rotation groups, to maximize sample size the observations for all 7 rotation groups spanning 2004 to 2013 are included in the health regressions.

${ }^{18}$ An exception is Greece in the 2010-2013 decomposition, which we explore in more detail below. The full decomposition results per comparison and per rotation group are available upon request.
} 


\section{Results and discussion}

This section first examines the general trends in IRHI in the 7 countries under study between 2004 and 2013. We then separately study the role of the mobility and health inequality terms in IRHI changes before and after the financial crisis in 2008. Next we compare cross country differences in the transfer mobility terms and pension policies. Finally, the role of the austerity measures enacted in Greece on IRHI is explored.

\section{IRHI trends across 7 European countries}

Figure 1 shows how IRHI, as measured by the $\mathrm{CCl}$ and calculated using predicted health, has evolved between 2004 and 2013 for the 7 countries under study. The separate lines represent the three rotation groups used to span the period. The black bars show $95 \%$ confidence intervals. While the confidence intervals in figure 1 are informative about the sampling variability of the yearly point estimates of IRHI, our interest lies in examining the changes of IRHI between different periods. It is therefore useful to know if the changes in IRHI with respect to the base year are statistically significant, which is signified by the bold bars. ${ }^{19}$

We note both geographical and time patterns in the IRHI trends. Before 2008, IRHI was either increasing or showed no significant movements, whereas between 2010 and 2013 some countries experienced dramatic decreases. There seems to be a geographical pattern; IRHI in southern EU countries was initially rising before beginning to fall after approximately 2008. Continental countries saw much smaller changes in IRHI, and both Belgium and France experienced significant increases in IRHI in the 2010-2013 period.

The above suggests distinctive trends in IRHI before and after the "Great Recession". Figures 2-4 respectively show, for our sample of analysis, the trends in average total and market equivalized household incomes, unemployment and retirement rates, and the generalized Gini coefficient, calculated using both market and total income. Figure 3 reveals an increase in unemployment for Spain, Portugal and Greece between 2009 and 2010, where it continues to rise throughout the 20102013 period. Unemployment increases are only noticeable in Italy in the 2010-2013 period, while the continental countries appear unaffected. Patterns in equivalized income are less obvious, and appear mostly in the last rotation group in the southern countries, especially Greece.

\footnotetext{
${ }^{19}$ We do not check the statistical significance of changes across rotation groups. While they might be relevant (e.g. comparing the change in IRHI from the onset of the financial crisis), we only observe the same set of individuals over a period of 4 years.
} 


\section{Figure 1-IRHI trends}
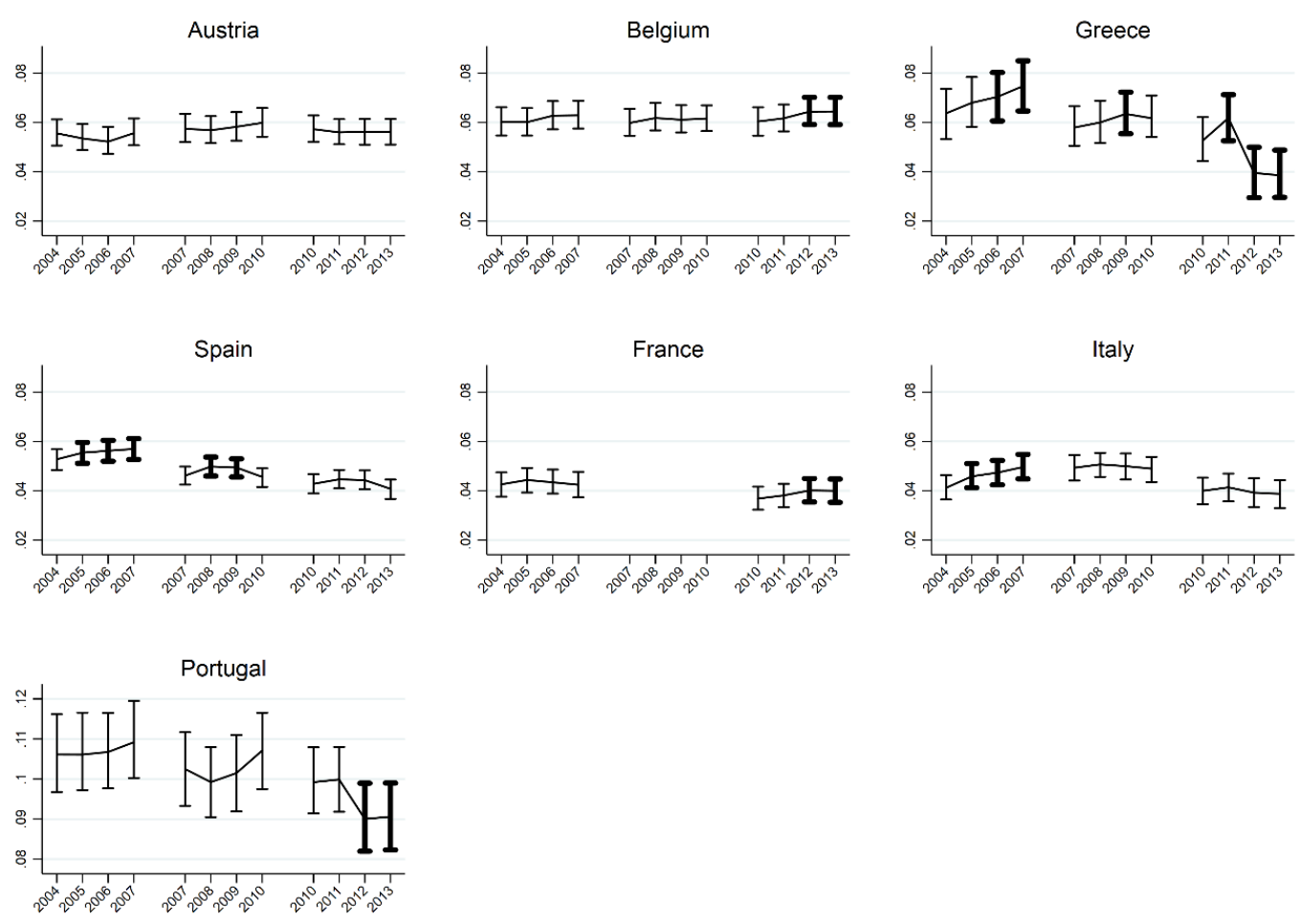

Figure shows, for each country, IRHI per year, per rotation group. Note the different scale of Portugal. Bold bars years in which change in $\mathrm{CCl}$ compared to base year is significant $(\mathrm{p}<0.05)$. $\mathrm{Y}$-axis: value of the $\mathrm{CCl}$.

Not surprisingly, in periods of economic growth the generalized Gini coefficient of market income tends to increase. The addition of transfers leads to lower absolute income inequality. For countries that suffered noticeable household income declines after the economic crisis, the generalized Gini index decreased.

Given these trends, we distinguish between 3 different periods in our analysis. Following Jenkins et al (2012), we consider the 2004-2007 period to be the pre-crisis period; a time of relatively normal growth for the 7 countries. We term the rotation group spanning 2007-2010 the crisis period. Finally, the post-crisis rotation period (2010-2013) is when consequences of the crisis are most obvious in southern countries, while large effects for household income, inequality and employment are absent for the continental countries.

Comparisons of household statistics in figures 2-4 and IRHI in figure 1 reveal that IRHI trends differ in good and bad economic times. Years in which countries experience steady income growth - such as Greece, Spain and Italy in the pre-crisis period - coincide with significant increases in IRHI. Average 

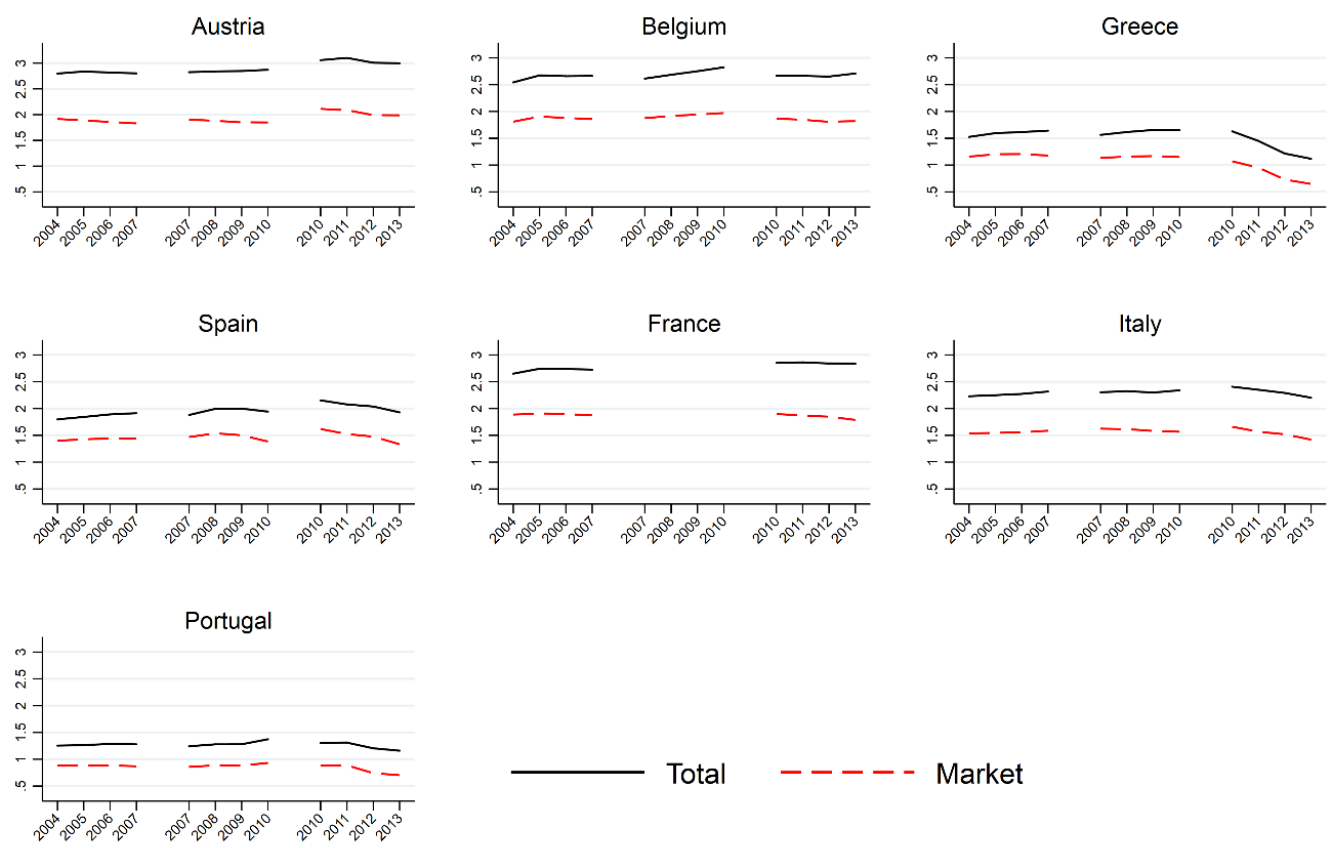

Figure shows, for each country, average total and market income per year, per rotation group.

income drops - and increasing unemployment - appear to be linked to decreases in IRHI; notably in Greece and Portugal in the post-crisis period. Our subsequent analysis is motivated by these observations: why does IRHI follow a pro-cyclical pattern, with significant increases (decreases) during times of economic growth (recession)? The decomposition will focus on the pre-crisis (2004-2010) and post-crisis (2010-2013) periods. This is because these periods encapsulate clear phases of economic growth or decline for countries, while the crisis period (2007-2010) often includes mixed periods of both. $^{20}$

\footnotetext{
${ }^{20}$ We present the decomposition results of the $2007-2010$ period in figure $A 1$ in the appendix.
} 
Figure 3 -Equivalent household income
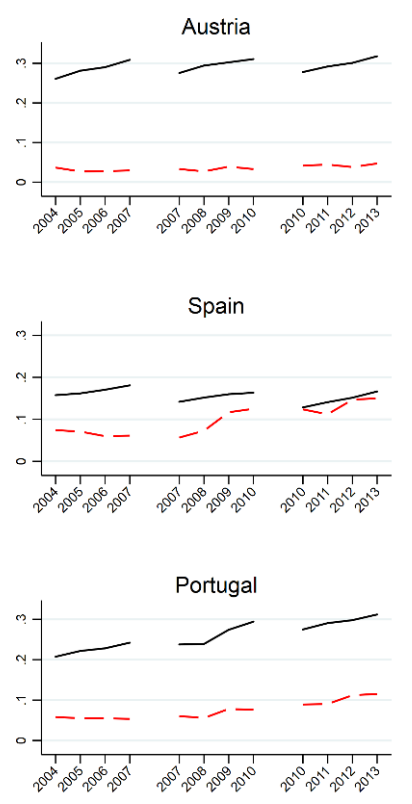
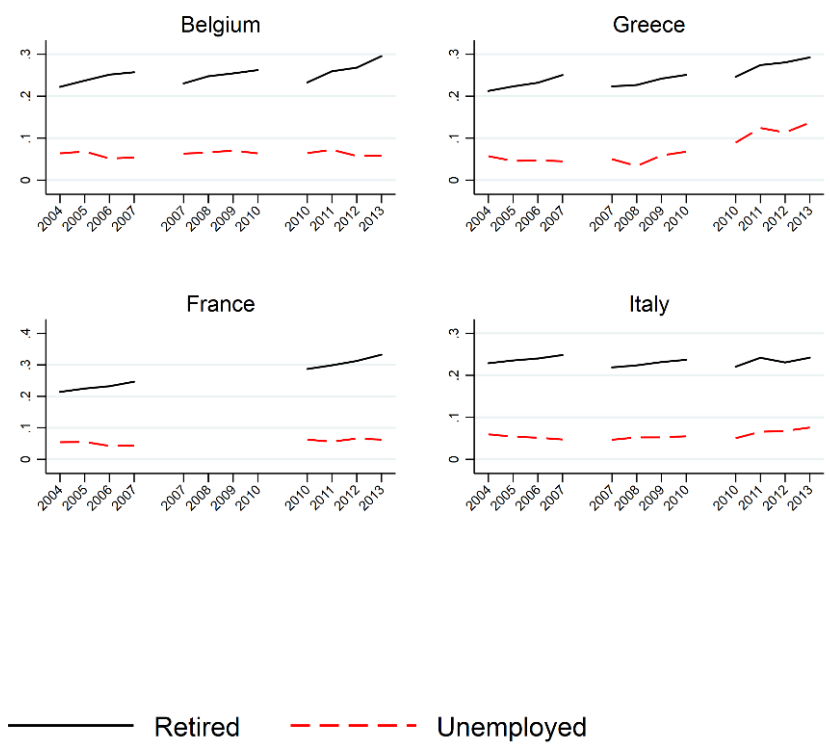

Figure shows, for each country, the average proportion of retired and unemployed individuals per year, per rotation group.

Figure 4 -Generalized Gin trends
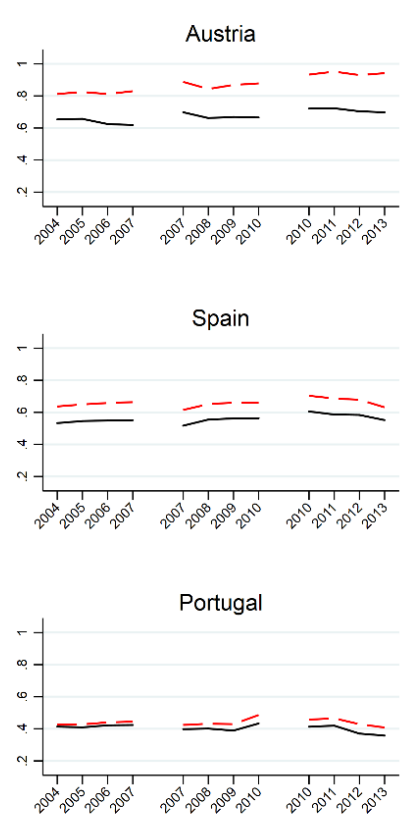
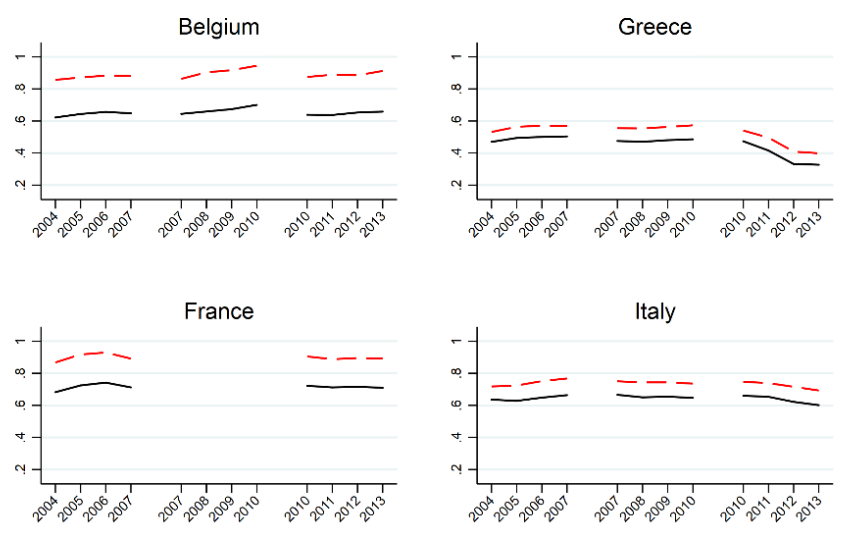

Figure shows, for each country, the value of the generalized Gin for total and market income per year, per rotation group.

16 


\section{Decomposition results}

Figures 5 and 6 depict the estimated income mobility and inequality change terms, respectively. The ageing and migration term proves to be unimportant for explaining IRHI evolution. ${ }^{21}$ Panels $\mathrm{A}$ and $\mathrm{B}$ in figure 5 show the results for, respectively, the pre-crisis and post-crisis rotation groups for all countries. The leftmost cluster of bars in panel A shows (in order from left to right) the contribution that market-related mobility (black), transfer-related mobility (grey) and total income mobility (white, and the sum of the previous two terms) had on IRHI changes in Austria between 2004 and 2007. The remaining clusters/panels have a similar interpretation for the different countries and rotation groups. In figure 6 each cluster of bars shows, per country, the effect that market-related inequality change, transfer-related inequality change and total inequality change (sum of the previous two terms) had on IRHI change in that rotation group.

The mobility terms are much larger in magnitude than the inequality terms, and thus appear to be the most important determinant of IRHI change. The reason for this is that the association between ageing and health is stronger than the association between income and health. ${ }^{22}$

\section{Mobility terms}

Figure 5 reveals that, across countries and periods, market mobility tends to be positive and sizable. In comparison - though usually negative - the size and sign of transfer mobility is more varied, and therefore it is often this term which leads to differences in the total mobility term across countryperiod comparisons.

Recall that the mobility terms can be further split into per-age/sex groups and per-region contributions (see equation 5). Doing so gives an indication of which age/sex group's income movements are influencing the direction of the separate mobility terms, and therefore gives insight into the patterns in figure 5. While we don't refer to these more detailed results explicitly in the main text, they inform much of the following discussion, and can be found in the appendix for each country, mobility term and for both the pre- and post-crisis period. ${ }^{23}$

\footnotetext{
${ }^{21}$ See figure $A 2$ in the appendix.

${ }^{22}$ For example, in Portugal, the country with the largest predicted health difference between the oldest and the youngest individuals, the difference between the individuals with the minimum and the maximum incomerelated health value is roughly the same as the difference in predicted health between a 16-25 year old and a 56-65 year old man. See table $A 3$ in the appendix.

${ }^{23}$ See tables A4-A10 in the appendix for the results per age/sex group. The results per region are supressed as they are small and not important to the decomposition, but are available upon request from the authors.
} 


\section{Figure 5-Income mobility terms}

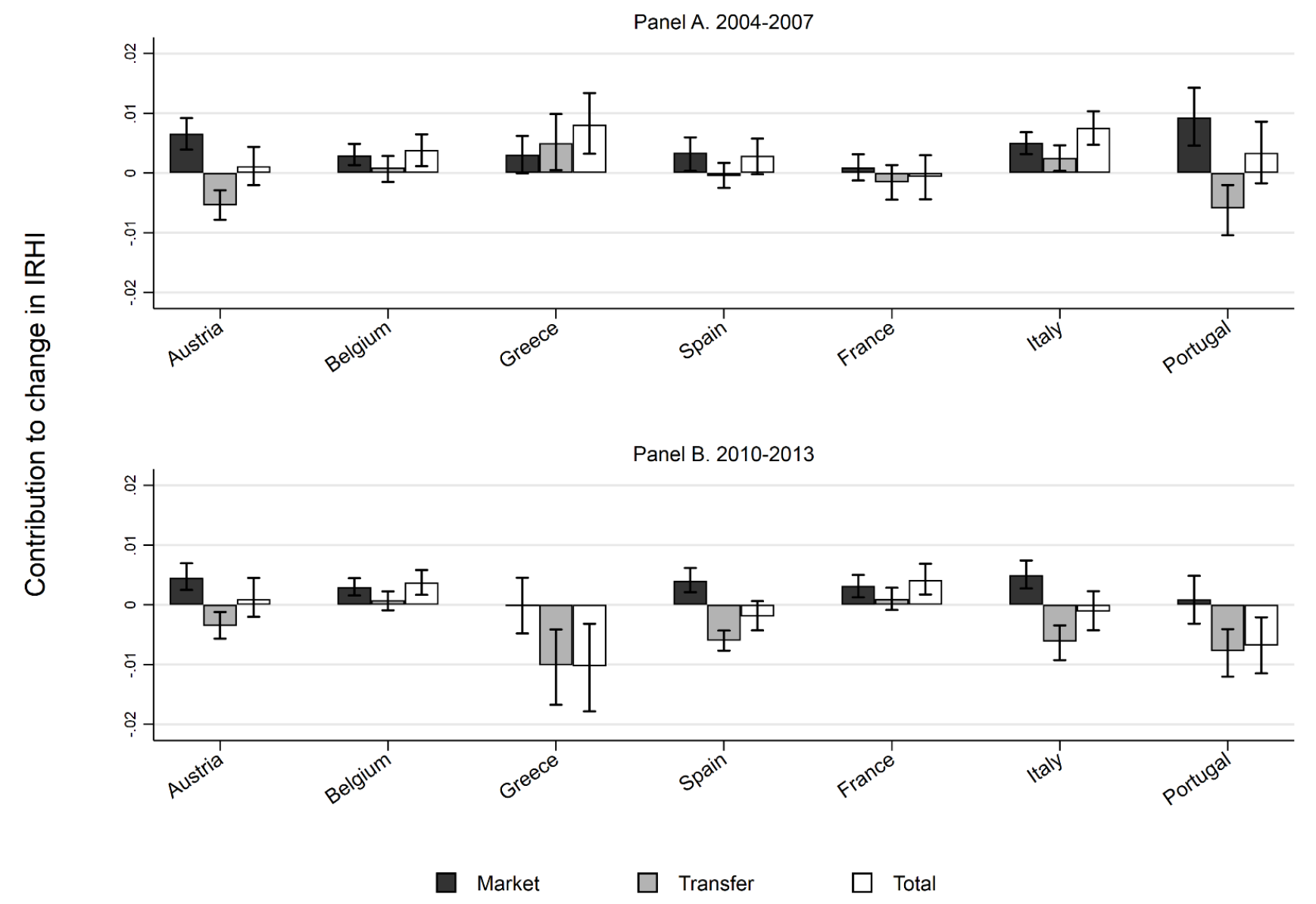

Figure shows decomposition results for income mobility terms (expressions 1 and 2 of equation (5), and their sum) for 2004-2007 and 2010-2013 rotation groups, per country. 


\section{Figure 6 - Income inequality terms}

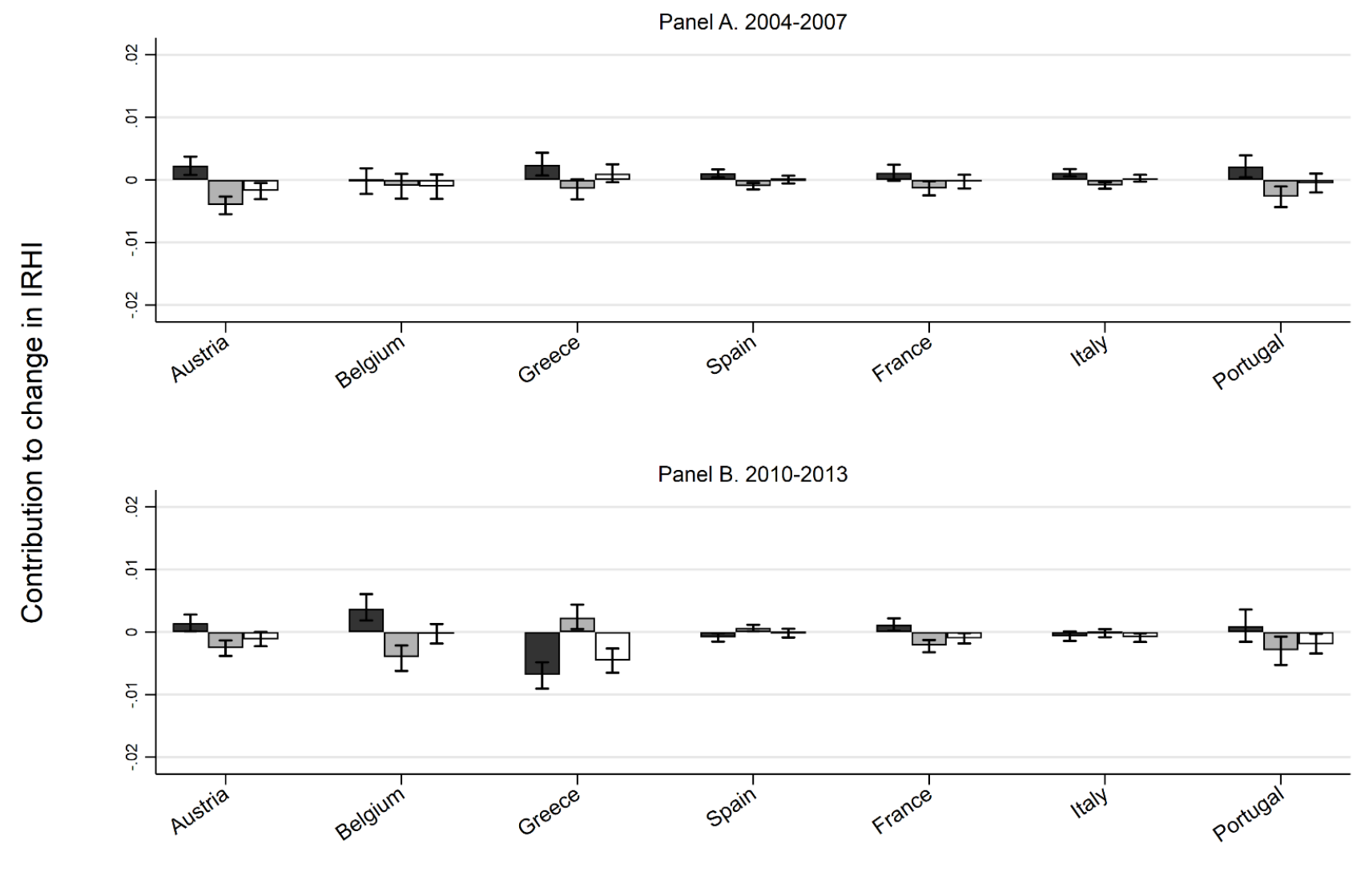

$\square$ Market $\square$ Transfer $\quad \square$ Total

Figure shows decomposition results for income inequality terms (expressions 3 and 4 of equation (5), and their sum) for 2004-2007 and $2010-2013$ rotation groups, per country. 
The reason for the IRHI increasing effect of market mobility is that improvements in market incomes help the youngest, and therefore healthiest, groups to climb the income ladder, thus increasing the disparities in health by market income. Greece and Portugal are amongst the only countries to not experience significantly positive market mobility in the post-crisis period, as market incomes no longer grew in this period and the very elderly were least affected by shrinking market incomes as they rely more than any other age group on pension incomes. Given the variation in transfer mobility, we distinguish between the following distinctive patterns.

First, one can distinguish between two types of periods and countries: (i) those in which transfer mobility fully compensates for the increase in IRHI caused by market mobility, such as in Austria (preand post-crisis), Portugal (pre-crisis period) and Spain and Italy (post-crisis), and (ii) periods and countries in which transfer mobility is close to zero, such as in Belgium and France (pre- and postcrisis), and Spain (pre-crisis). Our results show that transfer mobility tends to be IRHI reducing, as transfers mainly consist of pensions, which disproportionately benefit older and relatively less healthy groups. However, the crucial difference between the above two patterns is the income position of the very elderly $(75+)$ compared to young age groups. We return to this observation below.

Second, there are countries for which transfer mobility is large and positive, such as Italy and Greece pre-crisis. Further decomposition of these terms reveals that this can be attributed to household structure. Rather than solely being enjoyed by the old, younger people in Italy and Greece also benefited from the large increase in pension incomes between 2004 and 2007. This is due to young individuals in these countries continuing to live at their parent's home, and therefore benefiting from their parent's (or grandparent's) influx in pension income upon the retirement of the elderly members of the household. This increase in transfer income for the young and the just-retired, and to the exclusion of the very-elderly, led to increasing income disparities between the healthy and the unhealthy, and therefore increased IRHI.

Lastly, there is a remarkable pattern for the southern countries post-crisis, whereby transfer mobility is large and negative in the final rotation group. This is most noticeable in Greece and Portugal, where this term "over-compensated" for market mobility. In such cases total income mobility is negative, and leading to decreases in IRHI between 2010 and 2013. This is due to the "stickiness" of pensions relative to income from work - while the crisis led to a significant fall in the incomes of the young, the incomes of elderly (and, on average, unhealthier) pensioners were less affected. This generated a drop in IRHI. 
The market inequality change term tends to be positive in most countries and periods as market incomes tend to become more unequally distributed over time (see Figure 6). ${ }^{24}$ This occurs primarily for two reasons. Firstly, wage growth for the employed is typically positive. Second, as shown in figure 3 , the number of retirees in our panels - those who have much lower market incomes - gradually increases over time. Both of these phenomena lead to growing inequality in market incomes, and therefore also growing inequality in (predicted) market-income related health.

By contrast, the transfer-related inequality change terms tend to be negative, leading to IRHI decreases. This reflects two facts. First, the redistributive effect of transfers was negative in each year, i.e. market income-related health inequalities $\left(z_{i t}^{M} \theta\left(y_{i t}^{M}\right)\right)$ were always larger than total incomerelated health inequalities $\left(z_{i t} \theta\left(y_{i t}\right)\right)$. Second, the redistributive effect became larger (i.e. more negative) over time in most countries. We further find that the transfer-related inequality change terms compensate, in most countries and periods, the increase in market inequality change such that the changes in total income inequality change are usually close to zero.

The most important social transfers, in terms of change in the redistributive effect, are pensions. To demonstrate this, we repeat our decomposition and redefine transfer income to only include income from "old age benefits" and "survivor benefits" 25 , attributing the remaining transfer components to market income. The results are shown in the appendix (figure A3). Although the magnitudes change slightly for some countries, we observe much the same pattern as in figure 6 . This confirms that oldage and survivor benefits are the primary source of the increasingly redistributive effect of transfers over time.

In addition to transfers lowering IRHI through the mobility terms, our results identify a secondary IRHI reducing mechanism of transfers, and more specifically pensions. The $\theta()$ function describes the association between income and health conditional on age (and gender and region). Pensions reduce IRHI rises by providing income to, on average, poorer individuals, thereby reducing disparities in market income related health by improving the poor's (age-independent) health and income rank.

\footnotetext{
24 Portugal (post-crisis) is the only exception which combines an increase in market inequality change with a decrease of the generalized Gini index (see figure 4). This happens because the partial association between income and health - the $\theta()$ function - is steeper and more concave in Portugal than other countries (see Appendix Table A.3), and because average incomes were declining at the same time.

${ }^{25}$ The EU-SILC data is organized in such a way that separating these components, and focusing only on old age benefits, is impossible for the early rotation groups, such as the 2004-2007 rotation groups. However, for the years in which we can separate these components we find that the average contribution across all countries of old age benefits (pensions and other lump cash benefits afforded to those who have reached the required age) to household income is approximately $€ 7,000$ while for survivor benefits the average contribution is $€ 300$.
} 
Those that benefit from pensions are in worse health, not only because they are old, but also because their market incomes provide little market income-related health.

The smaller association between income and health relative to the association between age and health means that the pro-cyclical pattern seen in the mobility terms is less obvious for the inequality change terms. For each of the crisis countries, the effect of total-income inequality change does in fact switch from positive to negative (Greece, Spain, Italy) or becomes more negative (Portugal), when comparing the results from 2004-2007 to 2010-2013. However, with the exception of Greece these changes are quantitatively unimportant.

\section{Pension policies and IRHI}

The decomposition results highlight the particular importance of transfer mobility in determining the trends in IRHI: the income position of the old and very elderly (75+) as compared to younger age groups turned out to be crucial. A natural next step, and the goal of this section, is to check whether different trends in transfer mobility are related to differences in pension policies across countries. This is a first step towards understanding the role of pension policies for IRHI trends, although we acknowledge that the selection of 7 countries (see data section) inevitably restricts the scope of our analysis.

We restrict the analysis to the pre-crisis 2004-2007 period because - in contrast to later periods - this was a time of relatively normal economic growth. The severity of the crisis (and the policy reaction to it) in the post-crisis period differed substantially across countries. Restricting the period to a time of similar economic growth across countries facilitates a clearer cross country comparison of pension policies.

Panel A of table 3 shows the average change in levels and ranks of transfer incomes between 2004 and 2007 for different age groups (as defined in 2007). Transfer mobility in Portugal and Austria led to large reductions in IRHI because the very elderly enjoyed gains in transfer income (ranks) relative to working-age groups, especially the young. The effect of transfer mobility is muted in Belgium, Spain and France because the very elderly's relative transfer income position has stagnated. Finally, as discussed in the previous sections, in both Greece and Italy the transfer incomes of the young largely outperform those of the 65+ (Italy) and 75+ (Greece) age groups. Therefore, even in situations where newly retired individuals in the 56-65 group are compensated for their loss in market incomes, it is apparently not always sufficient for the net effect of transfer mobility to be IRHI reducing. Because of 
the large drops in predicted health as individuals' age, any relative income losses for those in the 6675 and especially those in the 75+ age categories will have IRHI increasing effects.

The phenomenon of relatively lower incomes of the very elderly $(75+)$ compared to more recent retirees is observed across Europe and elsewhere (OECD, 2008). In our setting, the key factor is how transfer incomes change the income position of the very elderly (i.e. how much they move up or down the income ladder), relative to others in the population - especially young groups. Differential growth in pensions compared to transfer payments to other age groups can be driven by several factors. First, if there is a gradual rise in pension contributions leading to more generous pensions for newly retired, the relative losses of the already-retired will be larger. This will be amplified if pension incomes from the recently retired are shared with younger household members while no similar sharing mechanism holds for the very elderly. Secondly, the indexation policy of pensions matters. If indexation is pegged 
Table 3 - Pension scheme characteristics and income redistribution

\begin{tabular}{|c|c|c|c|c|c|c|c|}
\hline & Austria & Belgium & Greece & Spain & France & Italy & Portugal \\
\hline Panel A. & Change in transfer income lev & anks 2004 & er age grc & & & & \\
\hline \multicolumn{8}{|c|}{ Change in transfer income levels 2004-2007 per age group (€) } \\
\hline $16-35$ & -314 & 323 & 486 & 81 & 988 & 358 & -87 \\
\hline $36-55$ & -72 & 352 & 327 & 519 & 730 & -34 & 187 \\
\hline $56-65$ & 4635 & 3187 & 3913 & 2341 & 2183 & 1602 & 1264 \\
\hline $66-75$ & 579 & 450 & 283 & 1241 & 1003 & 68 & 952 \\
\hline $76+$ & 1950 & -101 & 240 & 357 & 3 & 346 & 179 \\
\hline \multicolumn{8}{|c|}{ Change in transfer income ranks $2004-2007$ per age group $(€)$} \\
\hline $16-35$ & -21 & 6 & -13 & -13 & 5 & 7 & -19 \\
\hline $36-55$ & -16 & -6 & -8 & 0 & -3 & -5 & -4 \\
\hline $56-65$ & 68 & 39 & 67 & 33 & 36 & 27 & 23 \\
\hline $66-75$ & -11 & -16 & -22 & 1 & -9 & -20 & 24 \\
\hline $76+$ & 24 & -28 & -10 & -15 & -42 & -13 & -4 \\
\hline Panel B. & \multicolumn{7}{|c|}{ Pension generosity indicators (2007) } \\
\hline Replacement rate (lifetime) ${ }^{\mathrm{i}}$ & 0.91 & 0.63 & 1.1 & 0.85 & 0.63 & 0.78 & 0.69 \\
\hline Replacement rate (current)ii & 0.62 & 0.44 & 0.40 & 0.48 & 0.60 & 0.49 & 0.47 \\
\hline Pension wealthi & 9 & 5.6 & 13 & 10 & 8.1 & 8.4 & 7.9 \\
\hline Panel C. & \multicolumn{7}{|c|}{ Pension indexation policy (2004-2007) } \\
\hline
\end{tabular}

Panel A. shows the changes in transfer income levels and corresponding ranks between 2004 and 2007 for 5 different age groups. Panel B. shows 3 different sets of pension generosity indicators; the replacement rate as a ratio of the pension entitlement over the average annual life-time income of a hypothetical man who earned the mean income, the replacement rate as a ratio of the current income of pensioners over the current (2007) earnings of those aged between 50 and 59, and pension wealth, measured as the number of years of average annual income one can expect to receive upon retirement, taking into account life-expectancy, indexing rules and retirement age. Panel C. classifies the different indexation methods used across countries; "disc"= discretionary increases, "price" = price indexed, "price*" = price index for a select basket of goods, "prog." = indexed or discretionary increases favour poor pensions with larger increases. (i) Source: OECD (2005, 2007). (ii) Source: Eurostat (2018). 
to inflation, the real value of pensions will not increase. However, some countries use other indexing rules such as pegging pensions to average earnings, or "progressive" indexation, with smaller pensions enjoying higher proportional increases (OECD, 2009). Third, the age at which an individual retires will have consequences for the transfer mobility term. Because poor health rises sharply with age, the IRHI reducing effect of an increase in pension income at retirement will be larger the later-in-life an individual retires. ${ }^{26}$

In order to get a sense of the role of the different institutional settings, panel B of table 3 shows a number of different indicators of pension generosity in 2007; while panel C shows the type of indexing rules in effect per country during the 2004-2007 period. There is little evidence to suggest that generosity is related to the IRHI reducing effect of pensions. Austria consistently has the highest level of pension generosity, while Portugal has amongst the lowest, yet the transfer mobility for both of these countries significantly reduced IRHI. Belgium, France and Spain occupy different ranks according to the generosity measure used, yet for all of these countries transfer mobility is close to zero. As emphasized earlier, it is the relative changes in transfer income rank which are crucial to determining transfer mobility, and for those who are already retired pension generosity may do little to increase their income rank.

Indexation policy, shown in panel C, may also be important for differences in transfer mobility. Austria, which employs yearly discretionary increases in pensions, has adjusted pensions between 2004 and 2007 in a progressive manner (Whitehouse, 2009). Benefits rose with prices up until the median pension, while all pensions above the median were increased by a flat amount. Portugal had a similar progressive indexation. Belgium, France and Spain, applied pension indexation with prices, without any progressivity adjustments (OECD, 2007). Because the very elderly tend to have lower pension benefits, any progressivity in indexation will naturally favour them, thus plausibly increasing pension incomes ranks for these groups relative to younger groups, and reducing IRHI (OECD, 2009).

The age of new retirees in Austria between 2004 and 2007 is also important for transfer mobility. The large increase in transfer income for those aged above 75 is in part due to a number of newly retired pensioners who, in 2007, were aged 75 or more. According to calculations using our data, approximately $10 \%$ of the new retirees in this period fit this description in Austria. Thus, the influx of transfer income to these old age and relatively poor-health individuals increased the IRHI reducing effect of the rank mobility from transfers.

\footnotetext{
${ }^{26}$ However, due to large age brackets, our decomposition may fail to pick up the IRHI effect of small differences in the retirement age between countries. Moreover, the income position of the very elderly might not be directly affected by this; but only indirectly as compared to the newly retired.
} 


\section{Greek austerity measures and IRHI}

The most drastic policy changes in this period were enacted in Greece. In exchange for two bailout packages in 2010 and 2011, the Greek government introduced a wide ranging set of austerity measures. Among these were cuts in social transfers such as pensions and unemployment benefits, taxation of pensions above $€ 1,400$ a month by $5-10 \%$, and freezing mandatory increases in public pensions between 2011 and 2015. ${ }^{27}$

As mentioned above, the pattern for the inequality change term for Greece between 2010 and 2013 is noticeably different from other countries, as the transfer term is positive while the market term is negative. The decrease in absolute income inequality deriving from the large drop in income from work over this period means that market inequality change is negative, leading to reductions in IRHI. The positive sign for transfer inequality change indicates that the reduction in inequality between 2010 and 2013 was larger due to market income-related health changes than considering total income-related health changes. In other words: the redistributive effect of transfers declined as a result of cuts in social transfers due to the austerity measures, especially for pensions.

The consequences of the Greek austerity measures are less obvious when looking at the mobility results between 2010 and 2013, though they are visible in the 2010-2011 comparison when the transfer mobility term is large and positive. ${ }^{28}$ The immediate impact of the Greek austerity measures was a worsening of the incomes of the elderly relative to the young, as the drop in pensions between 2010 and 2011 was larger than the drop in income from work. This worsened the relative income position of older groups, and increased IRHI. However, the transfer mobility term switches sign to become negative between 2011 and 2012. This is due to the sudden nature of the cut in transfer incomes, compared to the more gradual decline in market incomes. While incomes were already falling in Greece between 2010 and 2011, it is in the subsequent two years that the largest falls occur (see figure 2). Between 2011 and 2013, incomes from work in Greece shrunk sufficiently to outweigh the initially IRHI increasing effects of the austerity measures.

\footnotetext{
27 OECD (2013) provides a list of pension reforms that occurred as a result of these austerity measures.

${ }^{28}$ See figure $A 4$ in the appendix.
} 


\section{Conclusion}

We believe we make a number of contributions to the literature on health inequalities. First, for a range of European countries, we show for the first time how IRHI have evolved between 2004 and 2013, a time period that covers the largest global economic contraction in the post-war era. We document distinct time and geographic trends in IRHI. Before the crisis, southern countries, and to a lesser extent continental countries, saw IRHI rising. After 2008, IRHI started falling in the southern countries that were most affected by the crisis. These European trends confirm the largely pro-cyclical pattern of IRHI documented for 2 countries (China and Spain) in earlier work (Baeten et al, 2013; Coveney et al, 2016).

Secondly, using a novel decomposition, we provide important new empirical regularities concerning IRHI growth. We find that market incomes tend to increase inequalities in health, while the relation between social transfers and IRHI reveals a more varied pattern, in some cases decreasing and in other cases increasing IRHI. This mixed pattern occurs because social transfers - most importantly pensions - are targeted at the elderly and other poor groups who are otherwise excluded from gains from income growth, but also because in some countries, the young tend to live longer in their parental household and therefore benefit from their pension benefits upon retirement. The decomposition also explains the -- perhaps initially puzzling -- finding that IRHI falls during crises. This occurs as the logical consequence of the stickiness of pensions relative to income from work, and the age-based income re-ranking effect that it generates.

Finally, we examine how government policies relate to IRHI change. We look at the heterogeneity in the IRHI decreasing effect of transfers across countries and time, and find that the most "successful" pensions payments (in terms of reducing IRHI) are those that do not leave the very elderly $(75+$ ) groups behind in times of income growth. Our results also demonstrate that the large reduction in pension payments that occurred between 2010 and 2013 due to the austerity measures in Greece initially coincided with an increase in IRHI, and is likely to have dampened the IRHI reducing effects of transfers in later years.

Based on these empirical findings, our results suggest that government transfer policies can and do appear to have a large effect on IRHI. Especially in times of crisis, pensions help to reduce IRHI by improving the relative income position of the elderly. In that sense, they can be argued to add a "silver lining" to the generally dark future prospects characterizing recessions. In periods of economic growth, however, transfers may not provide adequate protection for these groups. Key is the income protection afforded to the elderly, and in particular the very elderly, a group whose population share is likely to keep growing in the near future. Our results demonstrate that in situations where this group 
is excluded from gains, the net effect of transfers may no longer be IRHI reducing. But the finding also points at potential policy levers. Governments that are concerned with rising levels of IRHI should develop policies that improve the relative incomes of the very elderly. While our descriptive decomposition method can not causally assess the IRHI reducing effectiveness of alternative policies, our findings do suggest that pension generosity alone does not guarantee lower levels of IRHI. Other pension related policy options that favor the eldest groups, such as progressive indexation and appropriate discretionary increases, have greater potential to successfully reduce IRHI. Finally, it is worth noting that, while in general IRHI is pro-cyclical, the Greek experience shows that austerity measures can kill much of the IRHI reducing effect of pensions during crises, thereby removing most of the silver from the lining. 


\section{References}

Ásgeirsdóttir, T. L., \& Ragnarsdóttir, D. Ó. (2013) Determinants of relative and absolute concentration indices: evidence from 26 European countries. International Journal for Equity in Health, 12(1), 53.

Baeten, S., Van Ourti, T., \& Van Doorslaer, E. (2013) Rising Inequalities in Income and Health in China: Who is left behind?. Journal of Health Economics, 32(6), 1214-1229.

CDC (2013) Health Disparities and Inequalities Report - United States, 2013. Foreword. MMWR Supplements, 62(3), 1-2.

Coveney, M., García-Gómez, P., Van Doorslaer, E., \& Van Ourti, T. (2016) Health disparities by income in Spain before and after the economic crisis. Health Economics, 25(S2), 141-158.

Erreygers, G. (2009) Correcting the concentration index. Journal of Health Economics, 28(2), 504-515.

Erreygers, G., \& Van Ourti, T. (2011) Measuring socioeconomic inequality in health, health care and health financing by means of rank-dependent indices: a recipe for good practice. Journal of Health Economics, 30(4), 685-694.

Eurostat (2018) Aggregate replacement ratios for pensions (excluding other social benefits). Eurostat. Available at: http://appsso.eurostat.ec.europa.eu

European Commission. (2009) Solidarity in Health: Reducing Health Inequalities in the EU. Brussels, 20, 2009.

Jenkins, S. P., Brandolini, A., Micklewright, J., \& Nolan, B. (2012) The Great Recession and the Distribution of Household Income. Oxford University Press.

Lambert, PL (2001) The distribution and redistribution of income. Manchester University Press, Manchester $\left(3^{\text {rd }} \mathrm{Ed}\right)$.

Mackenbach, J. P., Kunst, A. E., Cavelaars, A. E., Groenhof, F., Geurts, J. J., \& EU Working Group on Socioeconomic Inequalities in Health. (1997) Socioeconomic inequalities in morbidity and mortality in Western Europe. The Lancet, 349(9066), 1655-1659.

Mackenbach, J. P., Stirbu, I., Roskam, A. J. R., Schaap, M. M., Menvielle, G., Leinsalu, M., \& Kunst, A. E. (2008) Socioeconomic inequalities in health in 22 European countries. New England Journal of Medicine, 358(23), 2468-2481.

OECD (2005) Pensions at a Glance 2005: Public Policies across OECD Countries, OECD Publishing, Paris. 
OECD (2007) Pensions at a Glance 2007: Public Policies across OECD Countries, OECD Publishing, Paris.

OECD (2008) Growing Unequal? Income Distribution and Poverty in OECD Countries. OECD Publishing, Paris.

OECD (2009) Pensions at a Glance 2009: Retirement-Income Systems in OECD Countries, OECD Publishing, Paris.

OECD (2013) Pensions at a Glance 2013: OECD and G20 Indicators, OECD Publishing, Paris.

Plotnick, R. (1981) A measure of horizontal inequity. The Review of Economics and Statistics, 2, 283288.

Regidor, E., Vallejo, F., Tapia Granados, J.A., Viciana-Fernández, F.J., de la Fuente, L., Barrio, G. (2016) Mortality decrease according to socioeconomic groups during the economic crisis in Spain: a cohort study of 36 million people. The Lancet, 388(10060), 2642-2652.

Ruhm, C. J. (2000) Are recessions good for your health? The Quarterly Journal of Economics, 115(2), 617-650.

Van Doorslaer E., Jones A. M. (2003) Inequalities in self-reported health: validation of a new approach to measurement. Journal of Health Economics, 22(1), 61-87.

Van Doorslaer E, Koolman X. (2004) Explaining the differences in income-related health inequalities across European countries. Health Economics, 13(7), 609-628.

Van Doorslaer, E., Wagstaff, A., Bleichrodt, H., Calonge, S., Gerdtham, U. G., Gerfin, M., \& O'Donell, O. (1997) Income-related inequalities in health: some international comparisons. Journal of Health Economics, 16(1), 93-112.

Van Ourti, T., Van Doorslaer, E., \& Koolman, X. (2009) The effect of income growth and inequality on health inequality: Theory and empirical evidence from the European Panel. Journal of Health Economics, 28(3), 525-539.

Whitehouse, E. (2009) Pensions, purchasing-power risk, inflation and indexation. OECD Social, Employment, and Migration Working Papers, (77) 
Appendix 
Table A1 - EU-SILC sample sizes available per country per year

\begin{tabular}{|c|c|c|c|c|c|c|c|c|c|c|c|c|c|c|}
\hline & \multicolumn{11}{|c|}{ Observations per year (unbalanced) } & \multirow[t]{2}{*}{$\begin{array}{l}\text { Missing rotation } \\
\text { groups }\end{array}$} & \multirow{2}{*}{$\begin{array}{l}\text { Missing } \\
\text { health } \\
\text { information }\end{array}$} & \multirow[t]{2}{*}{$\begin{array}{l}\text { Selected } \\
\text { countries }\end{array}$} \\
\hline & 2004 & 2005 & 2006 & 2007 & 2008 & 2009 & 2010 & 2011 & 2012 & 2013 & Total & & & \\
\hline Austria & 4,674 & 7,113 & 10,458 & 13,393 & 10,955 & 11,057 & 11,493 & 8,158 & 5,434 & 2,532 & 85,267 & & $0 \%$ & $\checkmark$ \\
\hline Belgium & 2,571 & 6,122 & 9,063 & 11,803 & 11,487 & 11,382 & 11,539 & 7,803 & 4,928 & 2,501 & 79,199 & & $1 \%$ & $\checkmark$ \\
\hline Bulgaria & 0 & 0 & 5,125 & 7,161 & 9,796 & 12,336 & 13,776 & 11,321 & 6,759 & 2,784 & 69,058 & 1,2 & $0 \%$ & \\
\hline Cyprus & 0 & 4,441 & 6,589 & 8,468 & 8,087 & 7,557 & 9,106 & 6,895 & 5,101 & 3,232 & 59,476 & 1 & $0 \%$ & \\
\hline $\begin{array}{l}\text { Czech } \\
\text { Republic }\end{array}$ & 0 & 8,628 & 14,856 & 19,293 & 22,644 & 19,713 & 18,209 & 12,890 & 9,033 & 4,565 & 129,831 & 1 & $15 \%$ & \\
\hline Denmark & 3,015 & 5,352 & 7,376 & 8,243 & 7,610 & 7,326 & 7,155 & 5,215 & 3,418 & 1,682 & 56,392 & 7 & $50 \%$ & \\
\hline Estonia & 2,232 & 3,415 & 6,982 & 10,005 & 10,849 & 11,308 & 11,213 & 7,844 & 5,068 & 2,646 & 71,562 & 7 & $15 \%$ & \\
\hline Greece & 3,526 & 6,405 & 9,831 & 12,345 & 14,119 & 15,043 & 14,784 & 9,429 & 5,475 & 2,573 & 93,530 & & $0 \%$ & $\checkmark$ \\
\hline Spain & 7,875 & 15,895 & 21,989 & 28,809 & 30,081 & 30,217 & 30,229 & 20,643 & 13,021 & 5,856 & 204,615 & & $1 \%$ & $\checkmark$ \\
\hline Finland & 4,018 & 7,528 & 10,602 & 13,578 & 13,222 & 12,569 & 15,551 & 11,428 & 7,878 & 4,861 & 101,235 & & $53 \%$ & \\
\hline France & 2,108 & 5,268 & 8,392 & 11,392 & 12,697 & 12,666 & 12,854 & 9,209 & 6,051 & 2,788 & 83,425 & & $0 \%$ & $\checkmark$ \\
\hline Croatia & 0 & 0 & 0 & 0 & 0 & 0 & 8,511 & 14,628 & 9,336 & 2,609 & 35,084 & $1,2,3,4$ & $42 \%$ & \\
\hline Hungary & 0 & 8,351 & 13,127 & 18,452 & 18,623 & 20,334 & 20,410 & 14,414 & 9,626 & 3,961 & 127,298 & 1 & $1 \%$ & \\
\hline Ireland & 1,500 & 3,667 & 6,020 & 6,111 & 4,531 & 1,870 & 2,668 & 2,306 & 1,498 & 812 & 30,983 & $4,5,6$ & $0 \%$ & \\
\hline Iceland & 1,561 & 2,980 & 4,140 & 5,398 & 5,427 & 5,409 & 5,658 & 3,998 & 2,480 & 1,185 & 38,236 & & $57 \%$ & \\
\hline
\end{tabular}

Table shows the number of observations available per country in the 2004-2013 longitudinal release of EU-SILC, and the criteria used to select countries for analysis. Data are presented with minimal cleaning, so numbers do not necessarily represent usable final sample sizes. In addition to observations per year, the numbers of the missing rotation groups between 2004 and 2013 are also listed, as well as the proportion of missing self-assessed health - our two main criteria for determining country selection. Of countries without missing information between 2004 and 2013, 3 countries are excluded due to high \% of missing health data: Iceland, Sweden and Finland. Table is continued below. 
Table A1 (cont.) - EU-SILC data available per country

\begin{tabular}{|c|c|c|c|c|c|c|c|c|c|c|c|c|c|c|}
\hline & \multicolumn{11}{|c|}{ Observations per year (unbalanced) } & \multirow[t]{2}{*}{$\begin{array}{l}\text { Missing rotation } \\
\text { groups }\end{array}$} & \multirow[t]{2}{*}{$\begin{array}{l}\text { Missing health } \\
\text { info }\end{array}$} & \multirow[t]{2}{*}{$\begin{array}{l}\text { Selected } \\
\text { countries }\end{array}$} \\
\hline & 2004 & 2005 & 2006 & 2007 & 2008 & 2009 & 2010 & 2011 & 2012 & 2013 & Total & & & \\
\hline Italy & 13,335 & 24,769 & 35,329 & 44,619 & 44,273 & 43,067 & 40,305 & 26,562 & 15,656 & 6,508 & 294,423 & & $1 \%$ & $\checkmark$ \\
\hline Lithuania & 0 & 4,910 & 7,969 & 10,913 & 10,472 & 11,211 & 11,603 & 8,225 & 5,636 & 2,874 & 73,813 & $1,2,5,6$ & $11 \%$ & \\
\hline Luxembourg & 7,602 & 7,522 & 7,726 & 7,745 & 7,513 & 6,136 & 8,409 & 7,276 & 6,542 & 1,680 & 68,151 & 7 & $0 \%$ & \\
\hline Latvia & 0 & 5,408 & 7,399 & 9,269 & 9,020 & 12,202 & 12,992 & 9,505 & 6,055 & 3,007 & 74,857 & 1 & $1 \%$ & \\
\hline Malta & 0 & 0 & 2,710 & 4,979 & 6,454 & 8,482 & 8,716 & 6,501 & 4,601 & 2,299 & 44,742 & 1,2 & $0 \%$ & \\
\hline Netherlands & 0 & 13,604 & 15,310 & 19,623 & 19,519 & 18,254 & 19,134 & 12,847 & 7,719 & 3,845 & 129,855 & 1 & $48 \%$ & \\
\hline Norway & 1,538 & 1,576 & 1,542 & 1,503 & 1,355 & 2,499 & 3,619 & 3,238 & 2,284 & 1,411 & 20,565 & 7 & $49 \%$ & \\
\hline Poland & 0 & 18,705 & 27,739 & 34,675 & 33,694 & 31,671 & 30,803 & 21,878 & 14,029 & 6,907 & 220,101 & 1 & $6 \%$ & \\
\hline Portugal & 2,946 & 5,456 & 7,180 & 7,852 & 6,692 & 6,184 & 6,471 & 5,915 & 4,956 & 3,005 & 56,657 & & $0 \%$ & $\checkmark$ \\
\hline Romania & 0 & 0 & 0 & 12,760 & 16,525 & 16,282 & 12,001 & 7,825 & 3,923 & 0 & 69,316 & $1,2,3,7$ & $0 \%$ & \\
\hline Sweden & 3,606 & 6,859 & 9,157 & 12,319 & 12,441 & 12,431 & 12,223 & 7,993 & 4,866 & 2,200 & 84,095 & & $50 \%$ & \\
\hline Slovenia & 0 & 15,702 & 20,616 & 24,546 & 24,908 & 25,379 & 25,239 & 16,505 & 9,666 & 4,348 & 166,909 & 1 & $64 \%$ & \\
\hline Slovakia & 0 & 6,424 & 9,377 & 12,027 & 12,524 & 13,472 & 13,524 & 9,877 & 6,584 & 3,137 & 86,946 & 1 & $0 \%$ & \\
\hline United Kingdom & 0 & 11,799 & 14,933 & 17,458 & 16,804 & 15,615 & 15,111 & 9,396 & 5,523 & 2,509 & 109,148 & 1 & $5 \%$ & \\
\hline
\end{tabular}

Table shows the number of observations available per country in the 2004-2013 longitudinal release of EU-SILC, and the criteria used to select countries for analysis. Data are presented with minimal cleaning, so numbers do not necessarily represent usable final sample sizes. In addition to observations per year, the numbers of the missing rotation groups between 2004 and 2013 are also listed, as well as the proportion of missing self-assessed health - our two main criteria for determining country selection. Of countries without missing information between 2004 and 2013, 3 countries are excluded due to high \% of missing health data: Iceland, Sweden and Finland. 
Table A2- Percentage of market and transfer income due to pensions and wages per rotation group

\begin{tabular}{|c|c|c|c|c|c|c|c|c|}
\hline & & Rot. 1 & Rot. 2 & Rot. 3 & Rot. 4 & Rot. 5 & Rot. 6 & Rot. 7 \\
\hline \multirow[t]{2}{*}{ Austria } & Pension \% & 40.77 & 42.03 & 44.11 & 41.73 & 39.64 & 39.85 & 38.77 \\
\hline & Wage \% & 70.91 & 69.38 & 66.15 & 68.49 & 66.62 & 67.11 & 67.40 \\
\hline \multirow[t]{2}{*}{ Belgium } & Pension \% & 32.69 & 33.20 & 35.32 & 32.95 & 32.80 & 30.65 & 31.06 \\
\hline & Wage \% & 68.35 & 66.96 & 65.10 & 66.95 & 67.94 & 66.87 & 66.85 \\
\hline \multirow[t]{2}{*}{ Greece } & Pension \% & 63.69 & 62.03 & 62.04 & 61.36 & 61.19 & 63.57 & 62.74 \\
\hline & Wage \% & 57.21 & 53.09 & 55.71 & 57.36 & 58.19 & 56.83 & 56.04 \\
\hline \multirow[t]{2}{*}{ Spain } & Pension \% & 54.85 & 60.21 & 54.49 & 52.70 & 48.63 & 37.18 & 33.12 \\
\hline & Wage \% & 77.57 & 78.53 & 80.88 & 80.33 & 79.95 & 73.59 & 71.92 \\
\hline \multirow[t]{2}{*}{ France } & Pension \% & 39.39 & 41.04 & 40.65 & 41.37 & 44.62 & 45.63 & 46.14 \\
\hline & Wage \% & 69.56 & 70.77 & 69.44 & 67.35 & 65.07 & 65.20 & 64.94 \\
\hline \multirow[t]{2}{*}{ Italy } & Pension \% & 57.59 & 55.91 & 55.00 & 52.47 & 54.16 & 55.34 & 54.87 \\
\hline & Wage \% & 60.48 & 62.73 & 61.23 & 62.63 & 62.38 & 60.88 & 61.76 \\
\hline \multirow[t]{2}{*}{ Portugal } & Pension \% & 41.73 & 45.42 & 45.69 & 43.12 & 46.00 & 47.51 & 45.91 \\
\hline & Wage \% & 75.13 & 76.66 & 77.94 & 78.79 & 77.75 & 79.21 & 78.18 \\
\hline
\end{tabular}

Table shows for each rotation group and country the percentage of transfer income from pensions (first row per country) and the percentage of (gross) market income from wages (second row per country), computed on the sample for which component information is available. Our data indicate that on average wages and pensions are the most important sources of income within market and transfer income, respectively. Our definition of pensions includes public pension payments, care allowances, disability cash benefits, lump sum payments at the time of retirement and other cash benefits. It does not include any payments from private pension plans, which enter the market income definition. Wages include all employee cash or near cash income. See table 2 for further information on the components of transfer and market income. 
$\underline{\text { Table A3 - Interval regression results }}$

\begin{tabular}{|c|c|c|c|c|c|c|c|}
\hline & (1) & (2) & (3) & (4) & (5) & (6) & (7) \\
\hline & Austria & Belgium & Greece & Spain & France & Italy & Portugal \\
\hline Eqinc & $0.0321 * * *$ & $0.0388 * * *$ & $0.0268 * * *$ & $0.0193 * * *$ & $0.0220 * * *$ & $0.0133 * * *$ & $0.0730 * * *$ \\
\hline Eqinc $^{2}$ & $-0.0027^{* * *}$ & $-0.0039 * * *$ & $-0.0031 * * *$ & $-0.0018 * * *$ & $-0.0017 * * *$ & $-0.0001 * * *$ & $-0.0106 * * *$ \\
\hline F $16-25$ & -0.0017 & $-0.0054^{*}$ & 0.00178 & -0.0011 & $-0.0084 * * *$ & -0.0014 & -0.0062 \\
\hline M 26-35 & $-0.0138 * * *$ & $-0.0179 * * *$ & $-0.0118 * * *$ & $-0.0132 * * *$ & $-0.0179 * * *$ & $-0.0137 * * *$ & $-0.0242 * * *$ \\
\hline F 26-35 & $-0.0119 * * *$ & $-0.0226 * * *$ & $-0.0082 * * *$ & $-0.0153 * * *$ & $-0.0245 * * *$ & $-0.0152 * * *$ & $-0.0263 * * *$ \\
\hline M 36-45 & $-0.0295 * * *$ & $-0.0310 * * *$ & $-0.0219 * * *$ & $-0.0267^{* * *}$ & $-0.0324 * * *$ & $-0.0276 * * *$ & $-0.0400 * * *$ \\
\hline F $36-45$ & $-0.0311^{* * *}$ & $-0.0391 * * *$ & $-0.0245 * * *$ & $-0.0291 * * *$ & $-0.0386 * * *$ & $-0.0312 * * *$ & $-0.0532 * * *$ \\
\hline M 46-55 & $-0.0541^{* * *}$ & $-0.0534 * * *$ & $-0.0422 * * *$ & $-0.0424 * * *$ & $-0.0537^{* * *}$ & $-0.0446 * * *$ & $-0.0699 * * *$ \\
\hline F 46-55 & $-0.0568 * * *$ & $-0.0530 * * *$ & $-0.0490 * * *$ & $-0.0499 * * *$ & $-0.0595 * * *$ & $-0.0510 * * *$ & $-0.0969 * * *$ \\
\hline M 56-65 & $-0.0834 * * *$ & $-0.0585^{* * *}$ & $-0.0785 * * *$ & $-0.0684 * * *$ & $-0.0670 * * *$ & $-0.0713^{* * *}$ & $-0.1160 * * *$ \\
\hline F 56-65 & $-0.0679 * * *$ & $-0.0589 * * *$ & $-0.0866 * * *$ & $-0.0813 * * *$ & $-0.0674 * * *$ & $-0.0806 * * *$ & $-0.1520 * * *$ \\
\hline M 66-75 & $-0.0827^{* * *}$ & $-0.0587^{* * *}$ & $-0.1190 * * *$ & $-0.0864 * * *$ & $-0.0906 * * *$ & $-0.1040 * * *$ & $-0.1510 * * *$ \\
\hline F 66-75 & $-0.0870 * * *$ & $-0.0747^{* * *}$ & $-0.1440 * * *$ & $-0.1140 * * *$ & $-0.0929 * * *$ & $-0.1250 * * *$ & $-0.1940 * * *$ \\
\hline M 76-85 & $-0.1220 * * *$ & $-0.0818^{* * *}$ & $-0.1860 * * *$ & $-0.1220 * * *$ & $-0.1330 * * *$ & $-0.1510 * * *$ & $-0.1950 * * *$ \\
\hline F 76+ & $-0.1480 * * *$ & $-0.0973 * * *$ & $-0.2160 * * *$ & $-0.1580 * * *$ & $-0.1290 * * *$ & $-0.1800 * * *$ & $-0.2480 * * *$ \\
\hline $\mathbf{N}$ & 57,028 & 50,848 & 66,192 & 139,372 & 61,932 & 195,552 & 59,084 \\
\hline
\end{tabular}

$* \mathrm{p}<0.05 * * \mathrm{p}<0.01 * * * \mathrm{p}<0.001$

Table shows the interval regression results, used to generate the ratio-scaled health variable and the coefficients of which are used in the decomposition. Eqinc refers to equivalized household income. The constant has been supressed, as well as the regional dummies because they are small and not important to the decomposition. Full regression results are available from the authors upon request. Robust standard errors used, clustered at the individual level. 
Figure A1 - Decomposition of 2007-2010 results

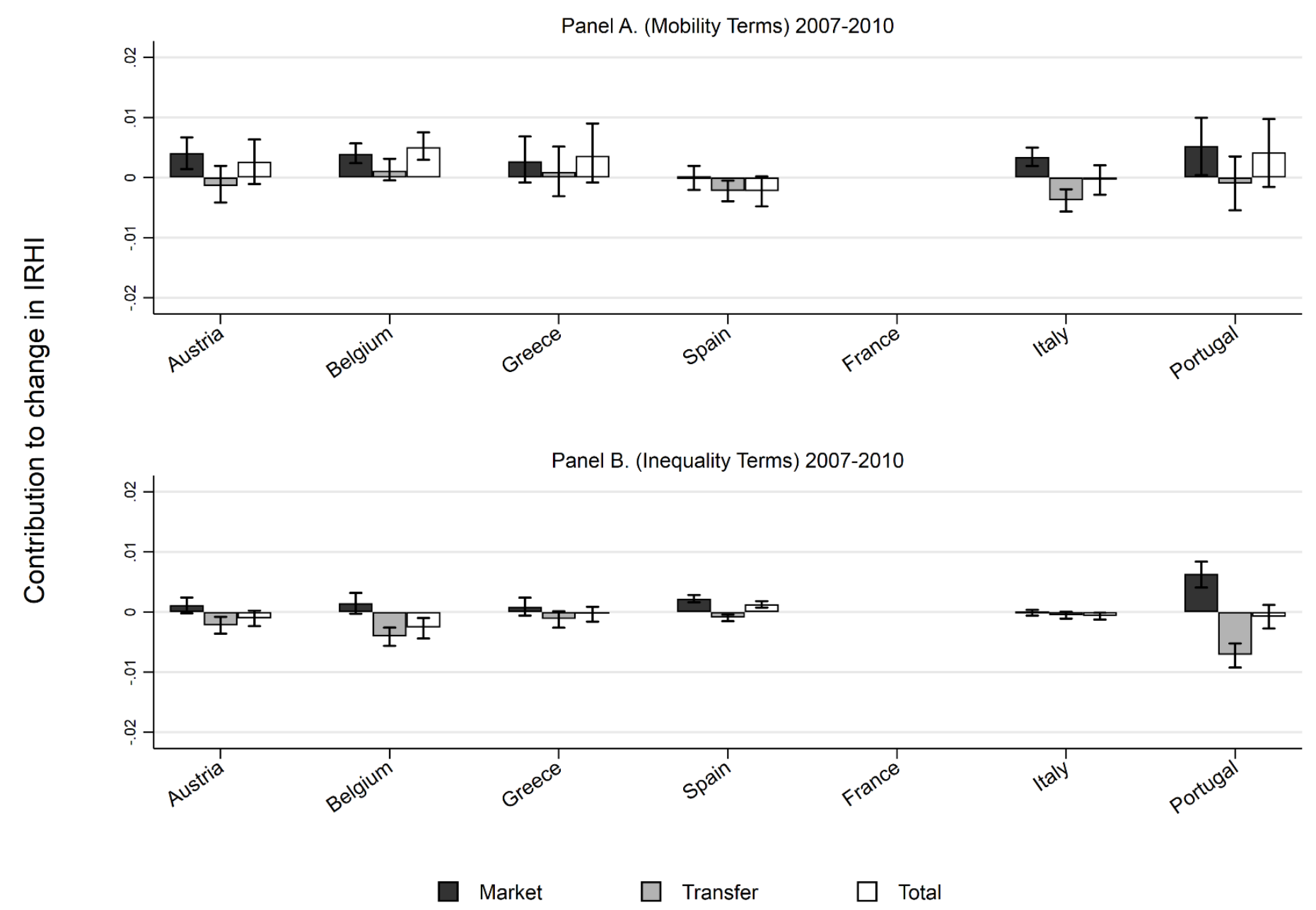

Figure shows the results of the inequality and mobility decomposition terms for the 2007-2010 rotation group. Notice that France is excluded due to data issues. See footnote 10. 
Figure A2 - Non-income factors

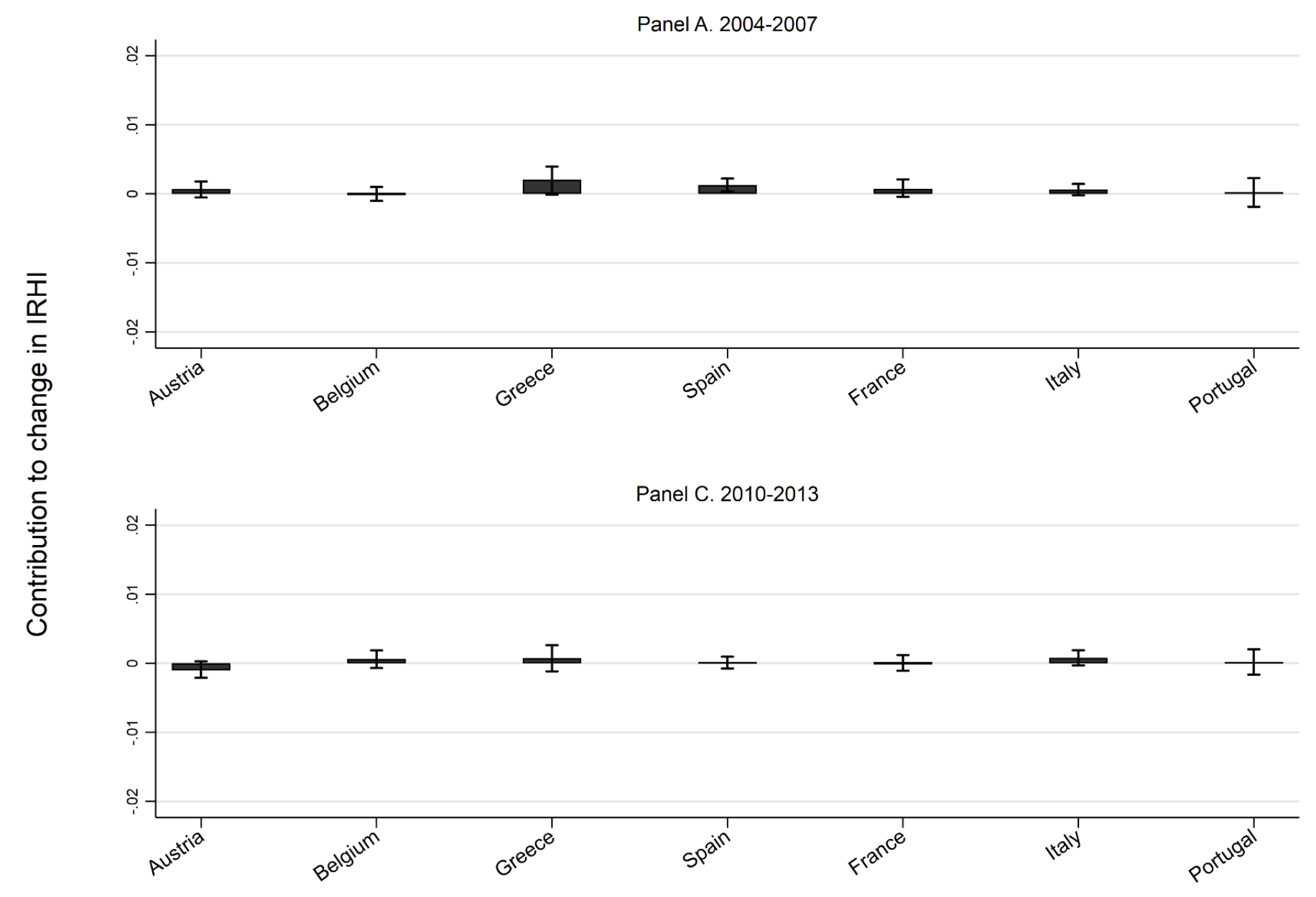

Figure shows the results of the ageing and migration decomposition term (term 5 in equation 5) for the 2004-2007 and the 2010-2013 rotation groups. 
Table A4 - Sub-mobility terms for Austria

\begin{tabular}{|c|c|c|c|c|c|c|c|c|c|c|c|}
\hline & \multicolumn{6}{|c|}{ Pre-crisis (2004-2007) } & \multicolumn{5}{|c|}{ Post-crisis (2010-2013) } \\
\hline & (1) & (2) & (3) & (4) & (5) & $(6)$ & (7) & (8) & (9) & $(10)$ & $(11)$ \\
\hline & Coeff. & Prop. & $\begin{array}{l}\text { Market } \\
\text { Weight }\end{array}$ & $\begin{array}{l}\text { Transfer } \\
\text { Weight }\end{array}$ & $\begin{array}{c}\text { Market } \\
\text { Income }(€)\end{array}$ & $\begin{array}{c}\text { Transfer } \\
\text { Income (€) }\end{array}$ & Prop. & $\begin{array}{l}\text { Market } \\
\text { Weight }\end{array}$ & $\begin{array}{l}\text { Transfer } \\
\text { Weight }\end{array}$ & $\begin{array}{c}\text { Market } \\
\text { Income (€) }\end{array}$ & $\begin{array}{c}\text { Transfer } \\
\text { Income (€) }\end{array}$ \\
\hline M 16-25 & - & 4.87 & $71.37^{* * *}$ & -8.802 & $2882.9^{*}$ & -429.8 & 5.16 & 37.83 & -23.89 & 1018.1 & -912.3 \\
\hline F 16-25 & -0.00172 & 4.94 & 12.65 & -22.37 & 56.78 & 91.47 & 3.1 & 27.09 & -29.42 & -498 & -988.5 \\
\hline M 26-35 & $-0.0138 * * *$ & 7.12 & -8.664 & -18.94 & -1855.7 & 64.65 & 7.79 & 0.567 & $-35.89 * *$ & -1260.8 & -294 \\
\hline F 26-35 & $-0.0119 * * *$ & 6.3 & $51.41 *$ & -23.03 & 2128 & -1042.6 & 6.89 & 11 & -13.58 & -1627.5 & 146.1 \\
\hline M 36-45 & $-0.0295 * * *$ & 10.47 & $36.14^{*}$ & $-17.28 *$ & 1237.3 & -472.7 & 7.42 & $37.25^{*}$ & 1.276 & 529.9 & 357.6 \\
\hline F 36-45 & $-0.0311 * * *$ & 10.6 & 10.39 & $-23.77^{* *}$ & -559.8 & -207.2 & 8.81 & 21.4 & -15.11 & -737.3 & -37.78 \\
\hline M 46-55 & $-0.0541 * * *$ & 9.37 & $35.45^{*}$ & -15.97 & 1151.8 & -324.9 & 10.33 & $24.95^{*}$ & -4.515 & 37.28 & -188.3 \\
\hline F 46-55 & $-0.0568 * * *$ & 9.53 & 0.00472 & -12.21 & -368.7 & 580.1 & 10.42 & -1.454 & -10.09 & -1187.9 & 225.2 \\
\hline M 56-65 & $-0.0834 * * *$ & 7.22 & $-77.99 * * *$ & $71.50 * * *$ & $-5070.7 * * *$ & $4621.3^{* * *}$ & 8.1 & $-53.67 * *$ & $36.37^{* *}$ & $-3966.7 * * *$ & $2758.0 * * *$ \\
\hline F 56-65 & $-0.0679 * * *$ & 9.15 & $-80.39 * * *$ & $58.81 * * *$ & $-5330.1 * * *$ & $4365.0 * * *$ & 8.94 & $-59.19 * * *$ & $46.78^{* * *}$ & $-4752.6 * * *$ & $3481.0 * * *$ \\
\hline M 66-75 & $-0.0827 * * *$ & 6.2 & 12.6 & -15.89 & -908.4 & 899 & 6.89 & -5.316 & 22.68 & -1347.7 & 1384.9* \\
\hline F 66-75 & $-0.0870 * * *$ & 6.28 & -3.961 & -10.06 & -1068.1 & 357.8 & 7.39 & -8.168 & 4.638 & $-1528.7^{*}$ & 841.7 \\
\hline M 76-85 & $-0.122 * * *$ & 3 & -55.14 & 18.39 & $-4198.6^{*}$ & 793.9 & 3.81 & -12.57 & -20.96 & -1960.7 & -4.252 \\
\hline F 76-85 & $-0.148 * * *$ & 4.96 & -16.5 & $37.10^{*}$ & -1013 & $2650.3^{* * *}$ & 4.94 & 8.501 & 8.034 & -284 & 282.5 \\
\hline
\end{tabular}

p<0.05** $p<0.01, * * * p<0.001$

Table shows components of the market and transfer mobility terms for Austria in the 2004-2007 and 2010-2013 decompositions. Column 1 shows the age/sex coefficient in the health regression, column 2 shows the proportion of individuals in each age/sex group in 2007, columns 3, 4, 5 \& 6 show the change between 2004 and 2007 for each age/sex groups in market income weights, transfer income weights, actual market incomes and transfer market incomes, respectively. Columns 7-11 show the identical information for the post-crisis 2010-2013 period. These changes are summarized by a no-constant regression where the change in the income weight/amount is regressed on a set of age/sex dummies which refer to the last wave in the rotation group. All currency amounts in 2013 euros. 
Table A5 - Sub-mobility terms for Belgium

\begin{tabular}{|c|c|c|c|c|c|c|c|c|c|c|c|}
\hline & \multicolumn{6}{|c|}{ Pre-crisis (2004-2007) } & \multicolumn{5}{|c|}{ Post-crisis (2010-2013) } \\
\hline & (1) & (2) & (3) & (4) & (5) & $(6)$ & (7) & (8) & (9) & $(10)$ & $(11)$ \\
\hline & Coeff. & Prop. & $\begin{array}{l}\text { Market } \\
\text { Weight }\end{array}$ & $\begin{array}{l}\text { Transfer } \\
\text { Weight }\end{array}$ & $\begin{array}{c}\text { Market } \\
\text { Income (€) }\end{array}$ & $\begin{array}{c}\text { Transfer } \\
\text { Income (€) }\end{array}$ & Prop. & $\begin{array}{l}\text { Market } \\
\text { Weight }\end{array}$ & $\begin{array}{l}\text { Transfer } \\
\text { Weight }\end{array}$ & $\begin{array}{c}\text { Market } \\
\text { Income }(€)\end{array}$ & $\begin{array}{c}\text { Transfer } \\
\text { Income (€) }\end{array}$ \\
\hline M 16-25 & - & 5.15 & 23.37 & -17.31 & $2301.2^{*}$ & -752.3 & 4.41 & 26.41 & -9.864 & 1581.2 & -418.3 \\
\hline F $16-25$ & $-0.00535^{*}$ & 4.96 & 35.22 & 20.25 & 2269.1 & 773.9 & 4.12 & 26.17 & -31.28 & 1004.7 & -537 \\
\hline M 26-35 & $-0.0180 * * *$ & 6.55 & 24.89 & 13.32 & 2023.3 & 734.3 & 6.53 & 16.92 & 19.37 & 1292.9 & 1057.0* \\
\hline F 26-35 & $-0.0226 * * *$ & 6.63 & $56.92^{* *}$ & 7.056 & $3219.5^{* *}$ & 413.4 & 6.83 & $45.38 * *$ & 29.90* & $2750.3^{* *}$ & 773 \\
\hline M 36-45 & $-0.0308 * * *$ & 9.51 & 19.63 & -2.297 & $1703.9 *$ & -15.73 & 9.68 & 13.3 & 4.89 & 1151.3 & 666.5 \\
\hline F 36-45 & $-0.0393 * * *$ & 10.36 & 1.277 & -10.44 & 855.4 & 109.6 & 9.21 & 11.75 & 10.32 & 1305.8 & 692.9 \\
\hline M 46-55 & $-0.0528 * * *$ & 11.51 & -10.69 & -11.94 & 131.5 & 181.9 & 9.05 & -8.712 & -7.544 & -584 & 214.8 \\
\hline F 46-55 & $-0.0528 * * *$ & 9.68 & -27.39 & 3.794 & -872.5 & $1172.2^{*}$ & 9.98 & -3.926 & -11.81 & 26.7 & 224.6 \\
\hline M 56-65 & $-0.0581 * * *$ & 7.06 & $-74.17^{* *}$ & $42.79 * *$ & $-2624.6^{*}$ & $3626.2^{* * *}$ & 7.44 & -29.29 & 5.4 & $-2356.0 * *$ & $1885.0 * * *$ \\
\hline F 56-65 & $-0.0582 * * *$ & 6.89 & $-43.04^{*}$ & $35.60 *$ & -1676.9 & $2736.7^{* * *}$ & 8.05 & $-58.41 * * *$ & $28.88 *$ & $-4399.6 * * *$ & $3286.4^{* * *}$ \\
\hline M 66-75 & $-0.0568 * * *$ & 5.61 & 6.525 & -11.55 & -209.1 & 616.2 & 5.91 & -0.961 & -13.87 & $-1658.2^{*}$ & $1009.6^{*}$ \\
\hline F 66-75 & $-0.0732 * * *$ & 6.58 & -0.13 & -20.41 & -1.682 & 307.7 & 6.91 & -15.82 & -10.21 & $-2345.9 * *$ & $1344.7^{* *}$ \\
\hline M 76-85 & $-0.0805^{* * *}$ & 3.74 & 26.43 & $-50.41 * *$ & 241.2 & -253.7 & 4.5 & -10.79 & -4.537 & $-1052.1^{*}$ & 808.9 \\
\hline F 76-85 & $-0.0958^{* * *}$ & 5.78 & 6.657 & -12.84 & 566.1 & -1.225 & 7.38 & 11.88 & $-29.06 *$ & -355.1 & 124.6 \\
\hline
\end{tabular}

Table shows different elements of the market and transfer mobility terms for Belgium in the 2004-2007 and 2010-2013 decompositions. Column 1 shows the age/sex coefficient in the health regression, column 2 shows the proportion of individuals in each age/sex group in 2007, columns 3, 4, 5 \& 6 show the change between 2004 and 2007 for each age/sex groups in market income weights, transfer income weights, actual market incomes and transfer market incomes, respectively. Columns 7-11 show the identical information for the post-crisis $2010-2013$ period. These changes are summarized by a no-constant regression where the change in the income weight/amount is regressed on a set of age/sex dummies which refer to the last wave in the rotation group. All currency amounts in 2013 euros. 
Table A6 - Sub-mobility terms for Greece

\begin{tabular}{|c|c|c|c|c|c|c|c|c|c|c|c|}
\hline & \multirow[b]{2}{*}{ (1) } & \multirow[b]{2}{*}{ (2) } & \multirow[b]{2}{*}{ (3) } & \multicolumn{8}{|c|}{ Post-crisis (2010-2013) } \\
\hline & & & & (4) & (5) & (6) & (7) & (8) & (9) & $(10)$ & $(11)$ \\
\hline & Coeff. & Prop. & $\begin{array}{l}\text { Market } \\
\text { Weight }\end{array}$ & $\begin{array}{l}\text { Transfer } \\
\text { Weight }\end{array}$ & $\begin{array}{c}\text { Market } \\
\text { Income }(€)\end{array}$ & $\begin{array}{c}\text { Transfer } \\
\text { Income }(€)\end{array}$ & Prop. & $\begin{array}{l}\text { Market } \\
\text { Weight }\end{array}$ & $\begin{array}{l}\text { Transfer } \\
\text { Weight }\end{array}$ & $\begin{array}{c}\text { Market } \\
\text { Income }(€)\end{array}$ & $\begin{array}{c}\text { Transfer } \\
\text { Income }(€)\end{array}$ \\
\hline M 16-25 & - & 3.72 & 34.27 & -13.09 & 1860.6 & 507.1 & 3.69 & -27.64 & $-55.38^{* *}$ & $-7245.6 * * *$ & -114.3 \\
\hline F $16-25$ & 0.00178 & 4.27 & 9.961 & 6.878 & 1737.7 & $1042.4^{*}$ & 3.74 & 21.2 & -7.963 & $-5665.0 * * *$ & 431.1 \\
\hline M 26-35 & $-0.0118^{* * *}$ & 8.05 & 32.33 & -0.111 & 1376.2 & $869.9 *$ & 7.8 & -2.049 & 10.89 & $-4715.2 * * *$ & -425.8 \\
\hline F 26-35 & $-0.00824 * * *$ & 9.03 & -4.421 & 18.27 & 10.24 & $1358.7^{* *}$ & 8 & 21.4 & -26.5 & $-4770.1 * * *$ & -71.14 \\
\hline M 36-45 & $-0.0219 * * *$ & 9.38 & $31.50^{*}$ & -9.901 & $1451.7^{* *}$ & 362.7 & 9.91 & 13.82 & $-42.87^{* * *}$ & $-5466.9 * * *$ & $-1011.4^{*}$ \\
\hline F $36-45$ & $-0.0245 * * *$ & 9.55 & 6.752 & $-15.18^{* *}$ & 690 & $372.6^{*}$ & 9.55 & 21.14 & $-30.62 * *$ & $-4849.5^{* * *}$ & -417.9 \\
\hline M 46-55 & $-0.0422 * * *$ & 8.43 & -11.23 & -11.85 & -487.7 & $559.0 * *$ & 8.34 & 2.382 & -16.29 & $-5343.5^{* * *}$ & -219 \\
\hline F 46-55 & $-0.0490 * * *$ & 8.47 & -20.83 & $24.94 *$ & -540.9 & $1680.9^{* * *}$ & 8.26 & -25.08 & 0.41 & $-5890.9 * * *$ & -160.6 \\
\hline M 56-65 & $-0.0785 * * *$ & 6.91 & -38.01 & $58.17^{* *}$ & -769.7 & $2796.7^{* * *}$ & 7.1 & -5.091 & 29.35 & $-4681.2^{* * *}$ & -465.3 \\
\hline F 56-65 & $-0.0866 * * *$ & 7.63 & -20.34 & 20.25 & -841.5 & $1750.1^{* * *}$ & 7.8 & -19.12 & 15.17 & $-3769.6 * * *$ & $-1462.7^{*}$ \\
\hline M 66-75 & $-0.119^{* * *}$ & 6.17 & -2.534 & -2.548 & -301.9 & $1298.3^{* * *}$ & 6.5 & $-68.47^{* *}$ & $75.60 * * *$ & $-3895.3 * * *$ & $-1784.4^{* * *}$ \\
\hline F 66-75 & $-0.144 * * *$ & 8.06 & -15.53 & -15.76 & -557.8 & $727.3^{* *}$ & 7.22 & -9.718 & $31.61^{*}$ & $-2340.9 * * *$ & $-2265.2^{* * *}$ \\
\hline M 76-85 & $-0.186 * * *$ & 4.51 & -5.529 & $-28.14^{* *}$ & -328.8 & 243.7 & 5.25 & $47.16^{* *}$ & 2.728 & $-1003.8^{* *}$ & $-2582.6 * * *$ \\
\hline F 76-85 & $-0.216 * * *$ & 5.81 & 18.04 & $-52.43^{* * *}$ & 83.33 & -202.7 & 6.85 & 24.65 & 22.04 & $-1134.3^{* *}$ & $-2079.0 * * *$ \\
\hline
\end{tabular}

Table shows different elements of the market and transfer mobility terms for Greece in the 2004-2007 and 2010-2013 decompositions. Column 1 shows the age/sex coefficient in the health regression, column 2 shows the proportion of individuals in each age/sex group in 2007, columns 3, 4, 5 \& 6 show the change between 2004 and 2007 for each age/sex groups in market income weights, transfer income weights, actual market incomes and transfer market incomes, respectively. Columns 7-11 show the identical information for the post-crisis $2010-2013$ period. These changes are summarized by a no-constant regression where the change in the income weight/amount is regressed on a set of age/sex dummies which refer to the last wave in the rotation group. All currency amounts in 2013 euros. 
Table A7 - Sub-mobility terms for Spain

\begin{tabular}{|c|c|c|c|c|c|c|c|c|c|c|c|}
\hline & \multicolumn{6}{|c|}{ Pre-crisis (2004-2007) } & \multicolumn{5}{|c|}{ Post-crisis (2010-2013) } \\
\hline & (1) & (2) & (3) & (4) & (5) & (6) & (7) & $(8)$ & (9) & $(10)$ & (11) \\
\hline & Coeff. & Prop. & $\begin{array}{l}\text { Market } \\
\text { Weight }\end{array}$ & $\begin{array}{l}\text { Transfer } \\
\text { Weight }\end{array}$ & $\begin{array}{c}\text { Market } \\
\text { Income }(€)\end{array}$ & $\begin{array}{c}\text { Transfer } \\
\text { Income }(€)\end{array}$ & Prop. & $\begin{array}{l}\text { Market } \\
\text { Weight }\end{array}$ & $\begin{array}{l}\text { Transfer } \\
\text { Weight }\end{array}$ & $\begin{array}{c}\text { Market } \\
\text { Income }(€)\end{array}$ & $\begin{array}{c}\text { Transfer } \\
\text { Income }(€)\end{array}$ \\
\hline M 16-25 & - & 4.53 & 27.52 & 0.956 & $1570.5^{* *}$ & 317.4 & 4.28 & 19.7 & $-26.74^{*}$ & $-2102.3^{* *}$ & 183.9 \\
\hline F 16-25 & -0.00107 & 4.14 & $55.99 * *$ & 2.05 & $2065.8^{*}$ & 309.2 & 4.03 & 23.54 & 6.371 & $-2059.4^{* * *}$ & $864.1 * *$ \\
\hline M 26-35 & $-0.0132 * * *$ & 7.77 & 25.61 & -11.61 & $2006.1^{* *}$ & 122 & 7.15 & 8.356 & -19.59 & $-3087.5 * * *$ & 319.5 \\
\hline F 26-35 & $-0.0153^{* * *}$ & 8.76 & 11.91 & $-23.75 * *$ & 1375.9 & -41.51 & 7.1 & $40.75^{*}$ & $-18.90^{*}$ & $-1581.7^{*}$ & 79.76 \\
\hline M 36-45 & $-0.0267 * * *$ & 10.06 & -13.36 & -6.835 & 343 & 325.3 & 10.44 & $30.92 * *$ & $-35.31 * * *$ & $-1656.6 * * *$ & -517.7 \\
\hline F 36-45 & $-0.0291 * * *$ & 10.91 & $25.30^{*}$ & -4.839 & $2003.3^{* * *}$ & 139.2 & 10.98 & 11.25 & $-28.66 * * *$ & $-2684.3^{* * *}$ & -261.7 \\
\hline M 46-55 & $-0.0424 * * *$ & 8.86 & 0.297 & 6.108 & 307.7 & $913.7^{* *}$ & 10.3 & 2.699 & -13.69 & $-3077.2^{* * *}$ & 321.7 \\
\hline F 46-55 & $-0.0499 * * *$ & 8.89 & 10.33 & 8.142 & 595.3 & 855.8* & 9.98 & -5.86 & -5.204 & $-3415.6^{* * *}$ & $831.0 * *$ \\
\hline M 56-65 & $-0.0684^{* * *}$ & 6.75 & $-64.46 * * *$ & 28.84 & $-2236.0 * *$ & $2303.5^{* * *}$ & 7.19 & $-47.15^{* *}$ & $46.54 * * *$ & $-4617.2^{* * *}$ & $2700.5^{* * *}$ \\
\hline F 56-65 & $-0.0813^{* * *}$ & 7.17 & $-68.26 * * *$ & $43.51^{* *}$ & $-2372.3^{* *}$ & $2450.9 * * *$ & 7.48 & $-66.19 * * *$ & $54.23 * * *$ & $-5573.0^{* * *}$ & $2601.6 * * *$ \\
\hline M 66-75 & $-0.0864 * * *$ & 5.72 & -29.81 & 6.225 & $-1383.0^{*}$ & $1475.9 * *$ & 4.82 & $-45.17^{*}$ & $44.31 * *$ & $-3962.5^{* * *}$ & $1130.4^{* *}$ \\
\hline F 66-75 & $-0.114 * * *$ & 6.3 & 4.318 & -14.71 & 124.8 & 609.6 & 6 & 0.64 & 9.993 & $-1625.1^{* *}$ & -109.5 \\
\hline M 76-85 & $-0.122^{* * *}$ & 3.88 & 11.2 & -13.52 & 327.1 & $548.1^{*}$ & 4.23 & 8.977 & $24.52^{*}$ & $-1446.9 * * *$ & 299.6 \\
\hline F 76-85 & $-0.158^{* * *}$ & 6.26 & 20.56 & -18.64 & 963 & 153.1 & 6.02 & 10.86 & $20.40^{* *}$ & $-1511.6^{* * *}$ & 422.9 \\
\hline
\end{tabular}

Table shows different elements of the market and transfer mobility terms for Spain in the 2004-2007 and 2010-2013 decompositions. Column 1 shows the age/sex coefficient in the health regression, column 2 shows the proportion of individuals in each age/sex group in 2007, columns 3, 4, 5 \& 6 show the change between 2004 and 2007 for each age/sex groups in market income weights, transfer income weights, actual market incomes and transfer market incomes, respectively. Columns 7-11 show the identical information for the post-crisis $2010-2013$ period. These changes are summarized by a no-constant regression where the change in the income weight/amount is regressed on a set of age/sex dummies which refer to the last wave in the rotation group. All currency amounts in 2013 euros. 
Table A8 - Sub-mobility terms for France

\begin{tabular}{|c|c|c|c|c|c|c|c|c|c|c|c|}
\hline & & \multicolumn{5}{|c|}{ Pre-crisis (2004-2007) } & \multicolumn{5}{|c|}{ Post-crisis (2010-2013) } \\
\hline & (1) & (2) & (3) & (4) & (5) & (6) & (7) & (8) & (9) & $(10)$ & $(11)$ \\
\hline & Coeff. & Prop. & $\begin{array}{l}\text { Market } \\
\text { Weight }\end{array}$ & $\begin{array}{l}\text { Transfer } \\
\text { Weight }\end{array}$ & $\begin{array}{c}\text { Market } \\
\text { Income }(€)\end{array}$ & $\begin{array}{c}\text { Transfer } \\
\text { Income }(€)\end{array}$ & Prop. & $\begin{array}{l}\text { Market } \\
\text { Weight }\end{array}$ & $\begin{array}{l}\text { Transfer } \\
\text { Weight }\end{array}$ & $\begin{array}{c}\text { Market } \\
\text { Income }(€)\end{array}$ & $\begin{array}{c}\text { Transfer } \\
\text { Income }(€)\end{array}$ \\
\hline M 16-25 & - & 5.5 & -10.08 & -9.324 & -901.9 & 1704.2 & 4.77 & 13.27 & -18.3 & -1341.3 & 459.6 \\
\hline F 16-25 & $-0.00842^{* * *}$ & 5.49 & -25.51 & $-41.17 *$ & -1087.2 & -256.7 & 3.74 & 48.06 & -4.055 & 1023.6 & -325.8 \\
\hline M 26-35 & $-0.0179 * * *$ & 8.35 & 28.27 & -6.367 & 1189.5 & 562.5 & 5.55 & 33.34 & 7.683 & 761.1 & 529.7 \\
\hline F 26-35 & $-0.0245^{* * *}$ & 8.86 & $43.67 * *$ & -2.626 & $2408.9 * *$ & 117.8 & 6.44 & $52.19 * * *$ & 4.266 & $1720.8^{*}$ & 301.5 \\
\hline M 36-45 & $-0.0324 * * *$ & 9.8 & 11.47 & -18.63 & 492.3 & -292.6 & 8.28 & $36.28 * *$ & -11.03 & $1713.6^{*}$ & -455 \\
\hline F 36-45 & $-0.0386 * * *$ & 10.86 & 29.6 & -0.112 & 1468.9 & 266.1 & 8.88 & $22.61^{*}$ & -13.62 & 1440.7 & -353.5 \\
\hline M 46-55 & $-0.0537 * * *$ & 8.77 & 7.619 & -1.254 & 737.6 & 945.6 & 8.31 & 0.878 & -12.98 & -1173.4 & 115.5 \\
\hline F 46-55 & $-0.0595 * * *$ & 9.42 & -26.98 & -13.95 & -1567.6 & 467.3 & 10.35 & -21.49 & -9.36 & $-2533.5^{* *}$ & $922.7^{*}$ \\
\hline M 56-65 & $-0.0670 * * *$ & 7.09 & $-76.14 * *$ & $76.78 * * *$ & $-3491.5^{*}$ & $4429.4^{* * *}$ & 9.64 & $-60.14 * * *$ & $46.81 * *$ & $-4465.9 * * *$ & $4095.9 * * *$ \\
\hline F 56-65 & $-0.0674 * * *$ & 7.8 & $-54.77^{*}$ & 57.38* & $-3215.3^{*}$ & $3443.4^{* * *}$ & 9.96 & $-70.55^{* * *}$ & $40.85^{* *}$ & $-4988.4 * * *$ & $3149.1^{* * *}$ \\
\hline M 66-75 & $-0.0906 * * *$ & 4.69 & 0.395 & -8.21 & -928.6 & 1070.2 & 6.42 & -7.063 & 0.235 & $-2034.6^{*}$ & $1623.5^{* *}$ \\
\hline F 66-75 & $-0.0929 * * *$ & 6.08 & 16.65 & $-33.08^{*}$ & 398.9 & -324.2 & 7.17 & 13.67 & -11.29 & -903.1 & $1322.3^{* *}$ \\
\hline M 76-85 & $-0.133^{* * *}$ & 2.98 & $40.53 * *$ & -18.6 & $1093.9^{*}$ & -432.4 & 4.47 & 19.5 & -22.6 & -239.6 & 337.2 \\
\hline F 76-85 & $-0.129 * * *$ & 4.3 & 16.11 & -3.895 & 103.1 & 706.1 & 6.02 & 15.26 & $-37.92 * * *$ & -136.4 & -202.9 \\
\hline
\end{tabular}

Table shows different elements of the market and transfer mobility terms for France in the 2004-2007 and 2010-2013 decompositions. Column 1 shows the age/sex coefficient in the health regression, column 2 shows the proportion of individuals in each age/sex group in 2007, columns 3, 4, 5 \& 6 show the change between 2004 and 2007 for each age/sex groups in market income weights, transfer income weights, actual market incomes and transfer market incomes, respectively. Columns 7-11 show the identical information for the post-crisis $2010-2013$ period. These changes are summarized by a no-constant regression where the change in the income weight/amount is regressed on a set of age/sex dummies which refer to the last wave in the rotation group. All currency amounts in 2013 euros. 
Table A9-Sub-mobility terms for Italy

\begin{tabular}{|c|c|c|c|c|c|c|c|c|c|c|c|}
\hline & \multirow[b]{2}{*}{ (1) } & \multicolumn{5}{|c|}{ Pre-crisis (2004-2007) } & \multicolumn{5}{|c|}{ Post-crisis (2010-2013) } \\
\hline & & (2) & (3) & (4) & (5) & (6) & (7) & (8) & (9) & $(10)$ & (11) \\
\hline & Coeff. & Prop. & $\begin{array}{l}\text { Market } \\
\text { Weight }\end{array}$ & $\begin{array}{l}\text { Transfer } \\
\text { Weight }\end{array}$ & $\begin{array}{c}\text { Market } \\
\text { Income }(€)\end{array}$ & $\begin{array}{c}\text { Transfer } \\
\text { Income }(€)\end{array}$ & Prop. & $\begin{array}{l}\text { Market } \\
\text { Weight }\end{array}$ & $\begin{array}{l}\text { Transfer } \\
\text { Weight }\end{array}$ & $\begin{array}{c}\text { Market } \\
\text { Income }(€)\end{array}$ & $\begin{array}{c}\text { Transfer } \\
\text { Income }(€)\end{array}$ \\
\hline M 16-25 & - & 3.8 & 22.53 & 1.636 & $1594.2^{* *}$ & 189.7 & 3.71 & 17.87 & $-37.88 * * *$ & $-2115.5^{* * *}$ & -432.9 \\
\hline F 16-25 & -0.00143 & 3.84 & $33.70 * *$ & $17.88^{*}$ & $2173.1 * * *$ & 214.1 & 3.84 & 5.191 & -5.838 & $-3006.8 * * *$ & 1014.6 \\
\hline M 26-35 & $-0.0137 * * *$ & 8.14 & $27.29 * *$ & -5.054 & $1897.2^{* * *}$ & -52.83 & 6.71 & $30.88^{*}$ & -8.388 & $-1385.9^{*}$ & 124.3 \\
\hline F 26-35 & $-0.0152^{* * *}$ & 7.88 & 16.02 & $16.28 * *$ & $1451.6^{* *}$ & $873.1 * * *$ & 5.71 & 16.04 & 8.223 & $-2100.9 * *$ & 833.4 \\
\hline M 36-45 & $-0.0276 * * *$ & 9.42 & 12.08 & $-13.87 * *$ & $1410.6^{* * *}$ & -317.7 & 8.24 & $30.65 * * *$ & $-27.52 * *$ & $-1505.0 * *$ & -496.9 \\
\hline F 36-45 & $-0.0312 * * *$ & 10.2 & 8.38 & -6.77 & $1220.8^{* *}$ & -284.8 & 9.1 & $29.72 * * *$ & $-29.46 * * *$ & $-1525.0 * *$ & $-688.7 * * *$ \\
\hline M 46-55 & $-0.0446 * * *$ & 8.18 & 6.458 & -1.24 & $1395.2^{* * *}$ & 100.3 & 9.43 & 10.16 & $-28.46 * * *$ & $-2632.2 * * *$ & -417 \\
\hline F 46-55 & $-0.0510^{* * *}$ & 7.95 & -5.579 & 8.953 & 725.2 & 475.4 & 10.62 & -5.887 & -2.869 & $-2964.2 * * *$ & $644.7^{*}$ \\
\hline M 56-65 & $-0.0713 * * *$ & 7.67 & $-36.18 * * *$ & $34.23 * * *$ & -870.5 & $1797.9 * * *$ & 8.02 & $-46.33 * * *$ & $34.16 * * *$ & $-4442.0 * * *$ & $1965.6 * * *$ \\
\hline F 56-65 & $-0.0806 * * *$ & 7.61 & $-23.22 *$ & $19.51 * *$ & -760.7 & $1447.6^{* * *}$ & 7.78 & $-43.99 * * *$ & $22.49 *$ & $-4229.7 * * *$ & $1543.4^{* * *}$ \\
\hline M 66-75 & $-0.104 * * *$ & 5.89 & -13.98 & -12.36 & $-993.7^{*}$ & 513.3 & 6.48 & $-25.89 *$ & 15.5 & $-2513.8 * * *$ & 331.6 \\
\hline F 66-75 & $-0.125 * * *$ & 7.1 & $-19.09 *$ & $-27.02 * * *$ & $-866.0 * *$ & -293.3 & 7.39 & $-27.28^{*}$ & $20.84^{*}$ & $-2427.6 * * *$ & 385.4 \\
\hline M 76-85 & $-0.151 * * *$ & 4.54 & -5.046 & $-20.55^{* *}$ & -317.2 & 314.9 & 5.11 & -0.0254 & $29.53 * *$ & $-1530.4^{* *}$ & $670.3^{*}$ \\
\hline F 76-85 & $-0.180 * * *$ & 7.79 & -9.769 & -9.822 & -383.4 & 333.6 & 7.85 & 18.03* & $14.25^{*}$ & $-817.2 *$ & 150.5 \\
\hline
\end{tabular}

Table shows different elements of the market and transfer mobility terms for Italy in the 2004-2007 and 2010-2013 decompositions. Column 1 shows the age/sex coefficient in the health regression, column 2 shows the proportion of individuals in each age/sex group in 2007, columns 3, 4, 5 \& 6 show the change between 2004 and 2007 for each age/sex groups in market income weights, transfer income weights, actual market incomes and transfer market incomes, respectively. Columns 7-11 show the identical information for the post-crisis $2010-2013$ period. These changes are summarized by a no-constant regression where the change in the income weight/amount is regressed on a set of age/sex dummies which refer to the last wave in the rotation group. All currency amounts in 2013 euros. 
Table A10 - Sub-mobility terms for Portugal

\begin{tabular}{|c|c|c|c|c|c|c|c|c|c|c|c|}
\hline & & \multicolumn{5}{|c|}{ Pre-crisis (2004-2007) } & \multicolumn{5}{|c|}{ Post-crisis (2010-2013) } \\
\hline & (1) & (2) & (3) & (4) & (5) & (6) & (7) & (8) & (9) & $(10)$ & (11) \\
\hline & Coeff. & Prop. & $\begin{array}{l}\text { Market } \\
\text { Weight }\end{array}$ & $\begin{array}{l}\text { Transfer } \\
\text { Weight }\end{array}$ & $\begin{array}{c}\text { Market } \\
\text { Income (€) }\end{array}$ & $\begin{array}{c}\text { Transfer } \\
\text { Income }(€)\end{array}$ & Prop. & $\begin{array}{l}\text { Market } \\
\text { Weight }\end{array}$ & $\begin{array}{l}\text { Transfer } \\
\text { Weight }\end{array}$ & $\begin{array}{c}\text { Market } \\
\text { Income (€) }\end{array}$ & $\begin{array}{c}\text { Transfer } \\
\text { Income }(€)\end{array}$ \\
\hline M 16-25 & - & 5.37 & 6.78 & 0.641 & -478 & $555.2^{*}$ & 3.62 & $40.45^{*}$ & -13.89 & -703 & -138.2 \\
\hline F 16-25 & -0.00621 & 4.38 & $51.55^{* *}$ & -15.07 & $1205.6 *$ & -59.6 & 3.8 & 19.68 & -10.75 & -1027 & 195 \\
\hline M 26-35 & $-0.0242 * * *$ & 7.83 & 6.407 & -13.9 & 368.1 & -82.51 & 6.04 & 23.16 & -26.78 & -901.7 & -557.5 \\
\hline F 26-35 & $-0.0263 * * *$ & 7.53 & $48.31^{*}$ & $-37.13^{*}$ & $1301.3^{* *}$ & -489.5 & 6.49 & 25.21 & -23.25 & -803.3 & 25.49 \\
\hline M 36-45 & $-0.0400 * * *$ & 8.25 & $38.70 * *$ & -9.996 & $1150.2^{* *}$ & -213 & 8.74 & -7.735 & $-31.05^{* *}$ & $-2638.2^{* * *}$ & 85.41 \\
\hline F 36-45 & $-0.0532 * * *$ & 9.09 & 2.019 & -15.25 & 13.51 & -230.6 & 10.25 & -0.255 & $-26.90 * * *$ & $-2441.4 * * *$ & 43.39 \\
\hline M 46-55 & $-0.0699 * * *$ & 8.89 & 0.851 & -2.633 & -291.4 & 493.1* & 8.34 & -6.581 & -3.896 & $-1873.0 * * *$ & 475.8 \\
\hline F 46-55 & $-0.0969 * * *$ & 9.7 & -2.91 & 7.746 & -392.7 & $589.4^{* *}$ & 9.49 & -0.275 & 4.726 & $-2092.6^{* * *}$ & $536.8^{* *}$ \\
\hline M 56-65 & $-0.116 * * *$ & 6.34 & $-59.86 * *$ & 35.16 & $-1547.2 * *$ & $1574.9 * * *$ & 7.82 & -27.77 & $39.38 * *$ & $-2781.4 * * *$ & $1272.1 * * *$ \\
\hline F 56-65 & $-0.152 * * *$ & 7.75 & $-48.50^{*}$ & 14.73 & $-1276.1^{* *}$ & $1085.7^{* * *}$ & 8.85 & $-39.20 *$ & $34.38^{*}$ & $-2684.6 * * *$ & $1050.9 * * *$ \\
\hline M 66-75 & $-0.151 * * *$ & 6.02 & -32.61 & $31.79 *$ & $-1024.1^{*}$ & $1159.5^{* * *}$ & 6.96 & $-31.33^{*}$ & $46.79 * *$ & $-2158.3^{* * *}$ & $907.7^{*}$ \\
\hline F 66-75 & $-0.194 * * *$ & 8.18 & -3.944 & 18.91 & -452.4 & $829.8^{* * *}$ & 7.5 & 3.48 & 16.25 & $-1248.7^{* * *}$ & 215.1 \\
\hline M 76-85 & $-0.195^{* * *}$ & 3.68 & 13.28 & 7.988 & -186.6 & 120.9 & 5 & $29.69 *$ & -26.12 & -326.1 & -447.6 \\
\hline F 76-85 & $-0.248 * * *$ & 6.99 & -8.314 & -13.2 & -587.6 & 179.3 & 7.1 & $29.60 *$ & 1.347 & -537.6 & 467.8 \\
\hline
\end{tabular}

$* \mathrm{p}<0.05, * * \mathrm{p}<0.01, * * * \mathrm{p}<0.001$

Table shows different elements of the market and transfer mobility terms for Portugal in the 2004-2007 and 2010-2013 decompositions. Column 1 shows the age/sex coefficient in the health regression, column 2 shows the proportion of individuals in each age/sex group in 2007, columns 3, 4, 5 \& 6 show the change between 2004 and 2007 for each age/sex groups in market income weights, transfer income weights, actual market incomes and transfer market incomes, respectively. Columns 7-11 show the identical information for the post-crisis 2010-2013 period. These changes are summarized by a no-constant regression where the change in the income weight/amount is regressed on a set of age/sex dummies which refer to the last wave in the rotation group. All currency amounts in 2013 euros. 


\section{Figure A3 - Inequality terms with transfer income consisting only of pensions}

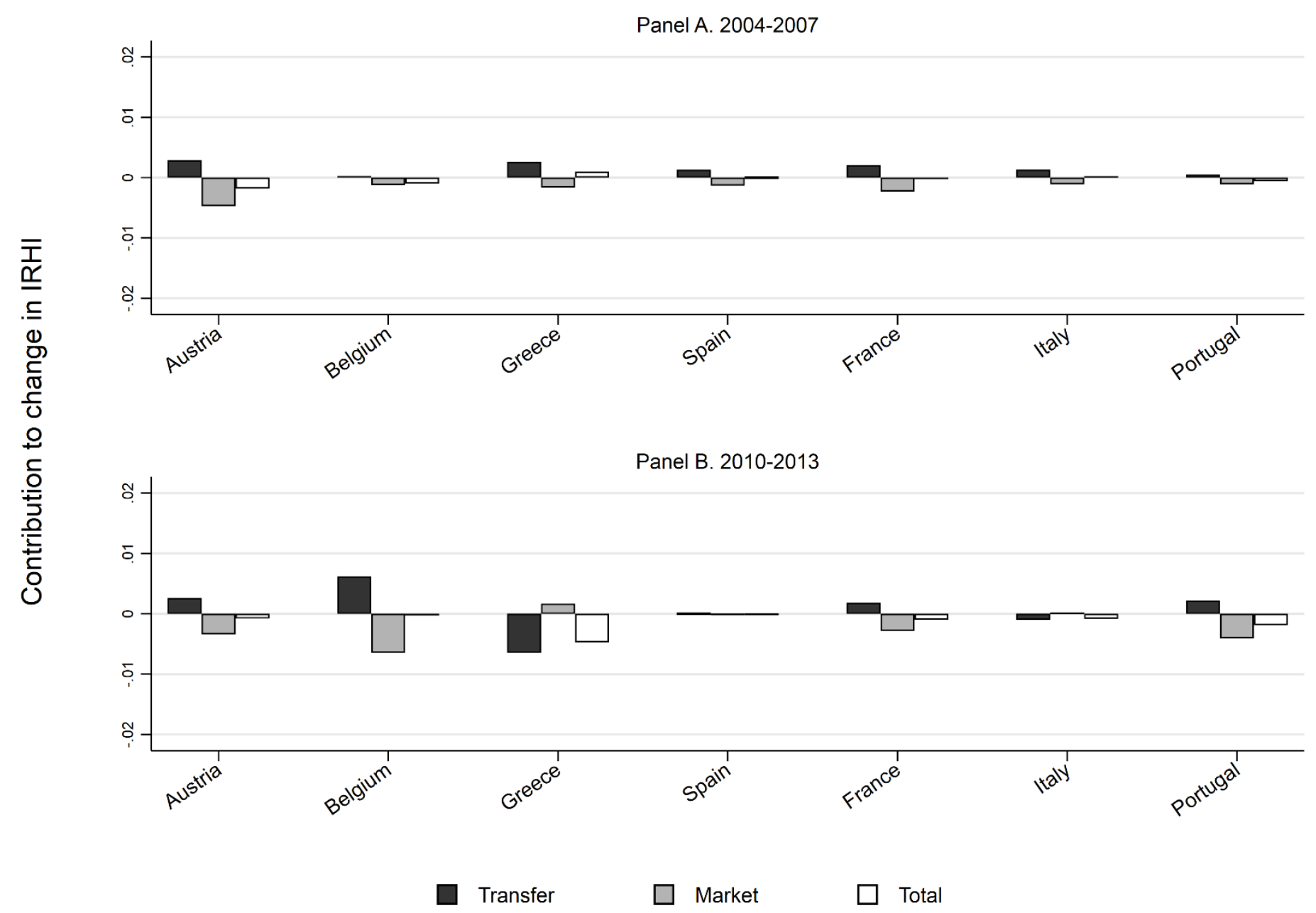

Figure shows the inequality term results of a decomposition where transfer income consists of pensions only, and where all other transfer components have been added to market income. 
Figure A4 - Year-by-year decomposition for Greece for 2010-2013 rotation group

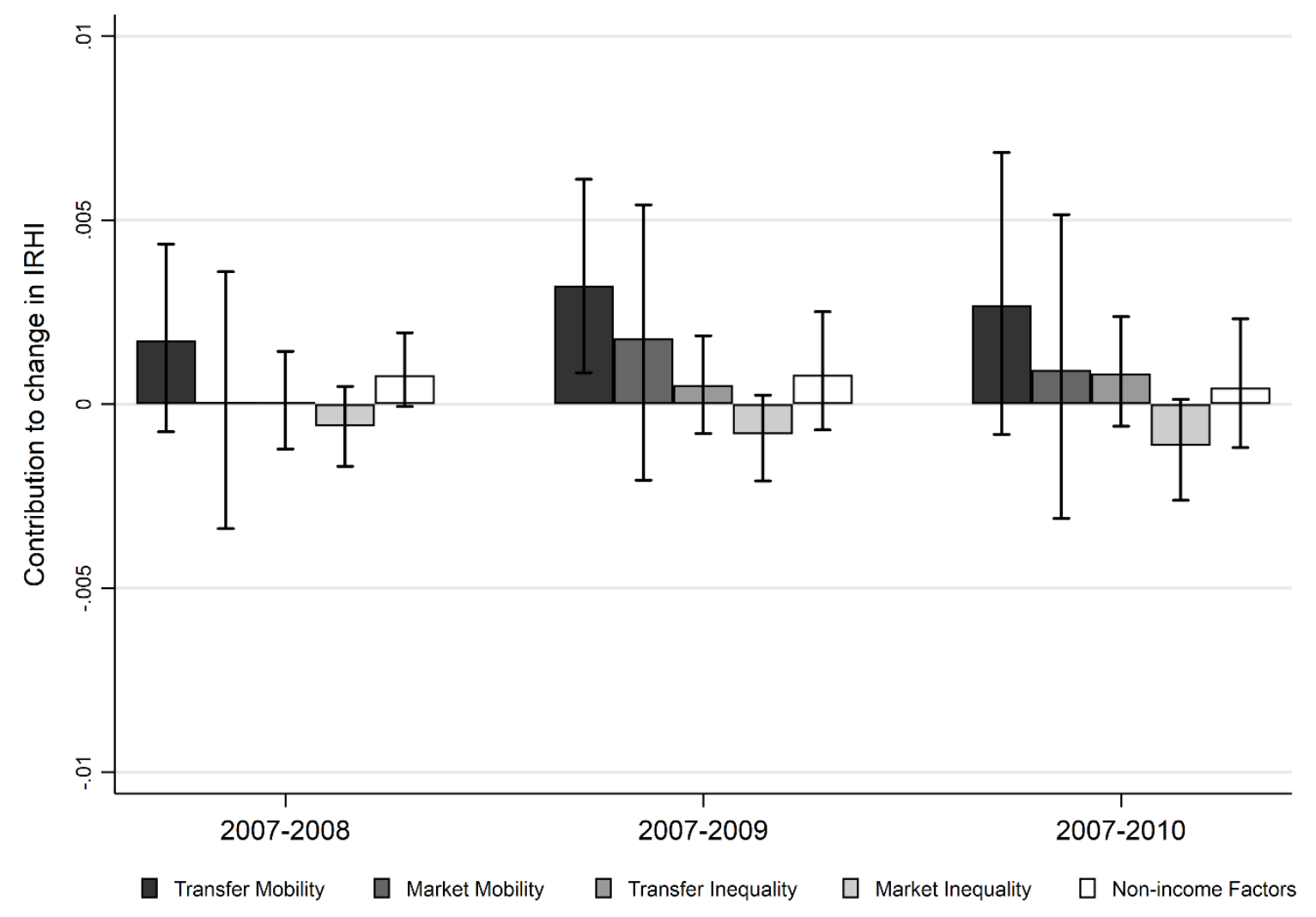

Figure shows the full decomposition results for Greece for each year of the 2010-2013 rotation group. 